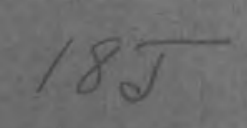

$\frac{\text { PNL-3087 }}{\text { UC-95d }}$

\title{
Evaluation of Resource Impact Factors Versus Social Cost Estimates in Determining Building Energy Performance Standard Levels
}
L. A. Nieves
R. J. Nesse
R. C. Adams
C. L. McDonald

December 1979

Prepared for the U.S. Department of Energy under Contract EY-76-C-06-1830

Pacific Northwest Laboratory Operated for the U.S. Department of Energy by Battelle Memorial Institute 


\title{
NOTICE
}

This report was prepared as an account of work sponsored by the United States Government. Neither the United States nor the Department of Energy, nor any of their employees, nor any of their contractors, subcontractors, or their employees, makes any warranty, express or implied, or assumes any legal liability or responsibility for the accuracy, completeness or usefulness of any information, apparatus, product or process disclosed, or represents that its use would not infringe privately owned rights.

The views, opinions and conclusions contained in this report are those of the contractor and do not necessarily represent those of the United States Government or the United States Department of Energy.

\author{
PACIFIC NORTHWEST LABORATORY \\ operated by \\ BATTELLF \\ for the \\ UNITED STATES DEPARTMENT OF ENERGY \\ Under Contract EY-76-C-06-1830
}

\author{
Printed in the United States of America \\ Available from \\ National Technical Information Service \\ United States Department of Commerce \\ 5285 Port Royal Road \\ Springfield, Virginia 22151
}

Price: Printed Copys

: Microfiche $\$ 3,00$

NTIS

- Pages Selling Price

$001-025 \quad \$ 4.00$

$026-050 \quad \$ 4.50$

$051-075 \quad \$ 5.25$

$076-100 \quad \$ 6.00$

$101-125 \quad \$ 6.50$

$126-150 \quad \$ 7.25$

$151-175 \quad 58.00$

$176-200 \quad 59.00$

$201-225 \quad 59.25$

$226.250 \quad 59.50$

$251-275 \quad \$ 10.75$

$276-300 \quad 511.00$ 


\title{
33679000531303
}

\section{EVALUATION OF RESOURCE IMPACT FACTORS \\ VERSUS SOCIAL COST ESTIMATES IN \\ DETERMINING BUILDING ENERGY \\ PERFORMANCE STANDARD LEVELS}

\author{
L. A. Nieves \\ R. J. Nesse \\ R. C. Adams \\ C. L. McDonald (a)
}

December 1979

Prepared for the U.S. Department of Energy under Contract EY-76-C-06-1830

Pacific Northwest Laboratory Richland, Washington 99352

(a) Now at Mathematical Sciences Northwest Bellevue, Washington 


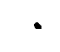

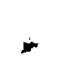

,

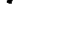




\section{SUMMARY}

The development of standards governing the designed energy consumption of buildings has been sought by congress to increase energy conservation. In determining what degree of energy conservation is desirable, efficiency and equity issues must be considered. Development of a performance standard that constrains design energy consumption to an economically efficient level requires identification of the least cost means of producing the desired building space conditioning characteristics. Accurate valuation of space conditioning inputs and outputs is also crucial to achieving economic efficiency in resource allocation.

There is some evidence that market prices of fuels used for building space conditioning and lighting have been less than the actual social cost of these fuels, and therefore energy system designs have been chosen that make inefficient use of resources. The RIF $x$ RUF multiplier concept, proposed by ASHRAE to fill the need for a factor by which to estimate the true cost of fuels, is evaluated and found lacking. Instead, estimates of social marginal cost are found to be the best means for incorporating the total cost of fuels in decisions determining design energy consumption for building space conditioning. This conclusion is supported by discussions of the historical patterns of fuel price distortion, identification of factors that influence the social costs of fuels, and estimates of the levels of social costs for conventional fuels.

The social, environmental and economic effects of fuel consumption may be incorporated into building design decisions most comprehensively through the use of a life cycle cost methodology in which fuel prices are represented by estimates of marginal social cost incurred per end use Btu. It is recommended that if feasible, a marginal social cost estimate that accounts for fuel production efficiencies be used in determining minimum life cycle costs for building space conditioning. Since the expense of developing social cost estimates for nonmarket components of social cost is not justified by the findings of the review of the literature related to price distortion, the use of the marginal cost of new fuel supplies is recommended as a proxy. Whether 
market or social cost is used, the cost estimate should be derived for states or smaller regions, because of the extent of variation in fuel supply costs. 
CONTENTS

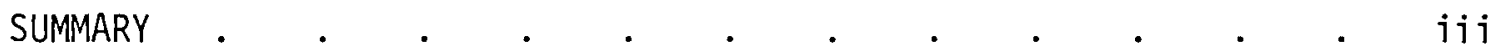

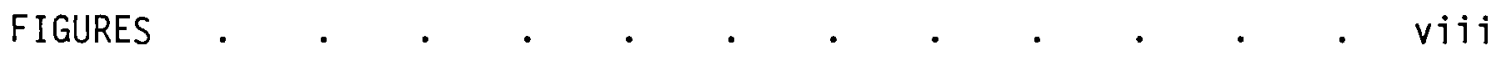

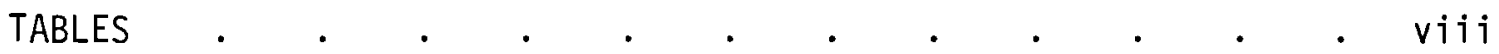

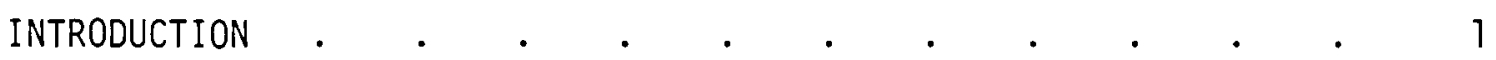

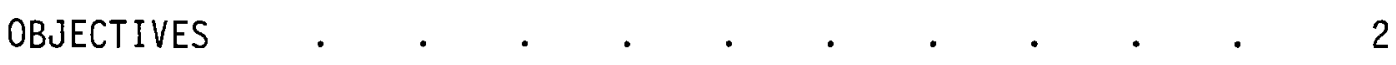

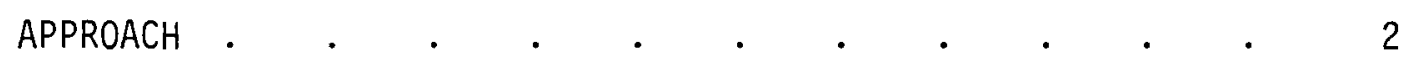

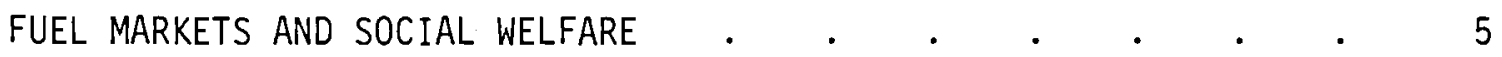

CAUSES OF MARKET FAILURE . $\quad$. $\quad$. $\quad$. $\quad$. 5

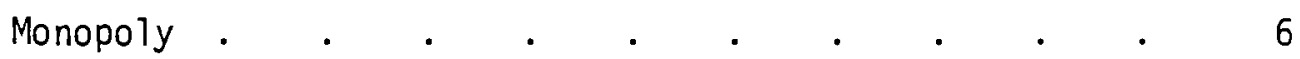

Externalities .

Price Controls and Regulation..$\quad$. $\quad . \quad$. $\quad .7$

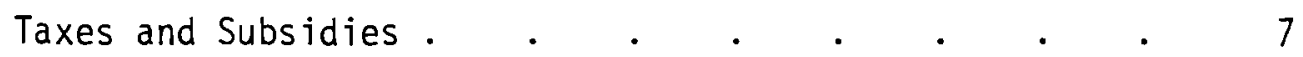

THE "SECOND BEST" PROBLEM

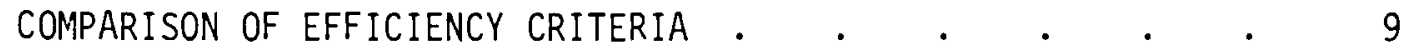

SOCIAL COST MODELS $. \quad . \quad . \quad . \quad . \quad . \quad . \quad . \quad . \quad . \quad 10$

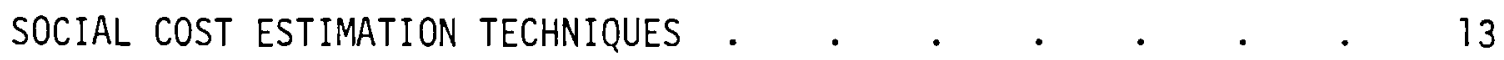

ESTIMATION METHODS FOR EXTERNAL COSTS . . . . . . 15

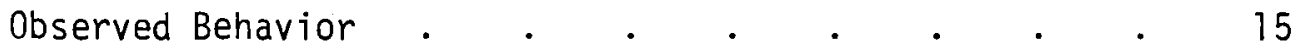

Direct Inquiries . $\quad . \quad . \quad . \quad . \quad . \quad . \quad 15$

Critique of Externality Valuing Methods . . . . . 16

METHODS OF ESTIMATING PRICE DISTORTION FROM MONOPOLY • • 17

Use of Average Costs as a Proxy for Unknown Marginal

Costs . . . . . . . . . . . 17 
Use of Profit Rates. $. \quad . \quad . \quad . \quad . \quad . \quad . \quad 17$

Use of Industry Concentration Ratios . . . . . 17

ESTIMATION OR PRICE DISTORTION DUE TO REGULATION $\quad . \quad \cdots \quad 18$

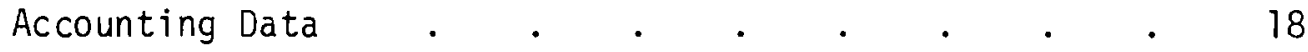

Econometric Modeling $\quad . \quad$. $\quad . \quad . \quad . \quad . \quad . \quad 19$

Comparison with Unregulated Prices . $\quad$. $\quad$. 19

METHODS OF ESTIMATING PRICE DISTORTION DUE TO TAXATION

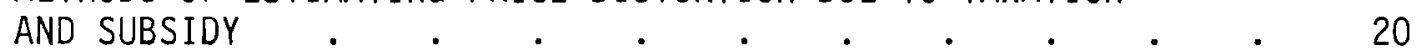

EMPIRICAL ESTIMATES OF SOCIAL COSTS

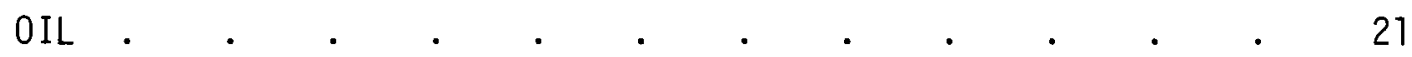

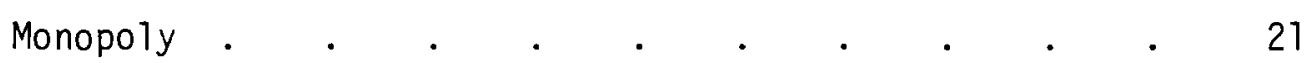

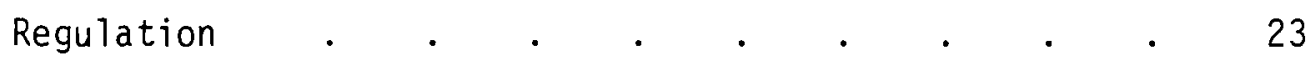

Taxation and Subsidies . $\quad . \quad$. $\quad . \quad$. $\quad . \quad 25$

Health Effects. . . . . . . . . . . 26

Environmental Effects $\quad . \quad$. $\quad . \quad . \quad . \quad . \quad . \quad 27$

Embargo Costs .

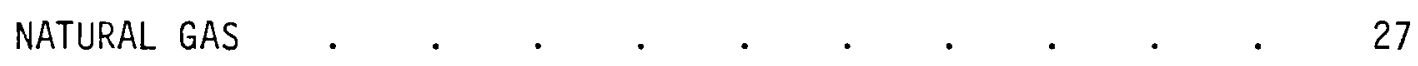

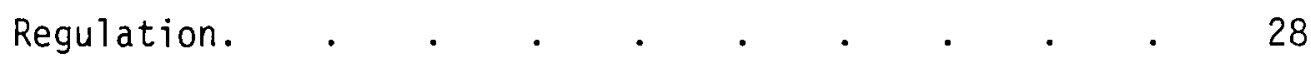

Monopoly . . . . . . . . . . . . . . 33

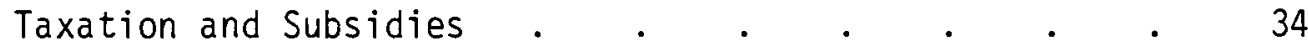

Health and Environmental Effects . . . . . . 34

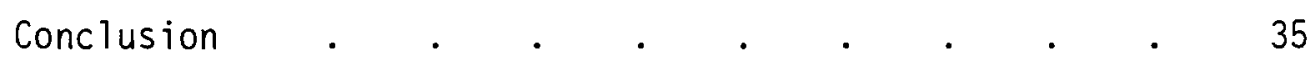

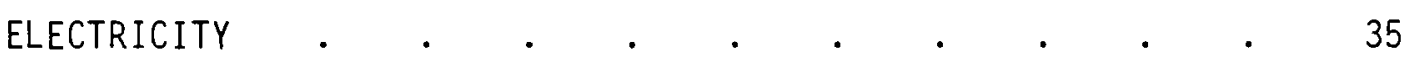

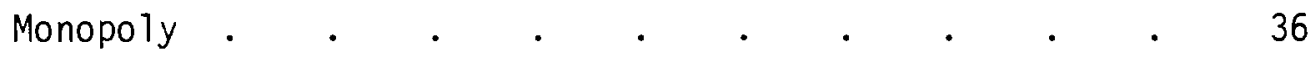

Taxation and Subsidies . $\quad . \quad$. $\quad . \quad$. 38

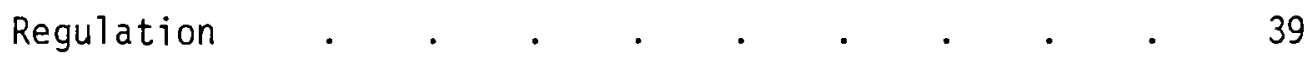


Public Utility Regulation . . . . . . . . 40

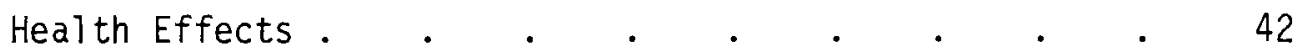

Environmental Effects . . . . . . . . . 44

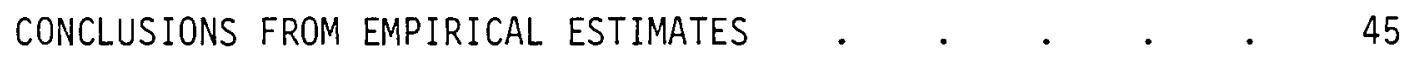

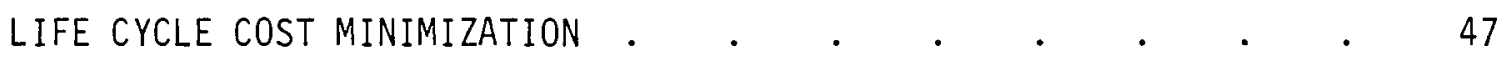

LIFE CYCLE COST MODEL FORMULATION

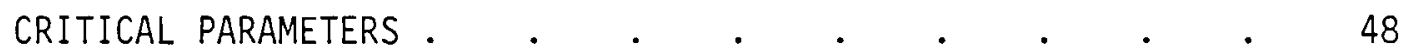

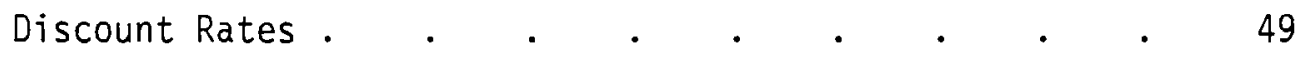

Discount Period . $\quad . \quad$. $\quad . \quad$. 50.50

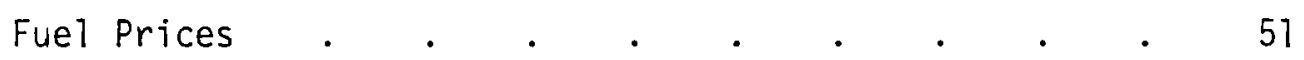

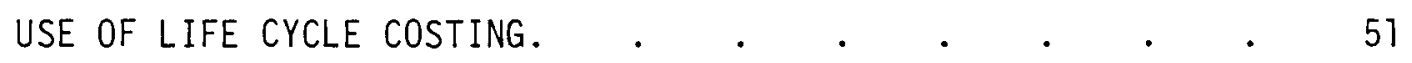

EVALUATION OF RESOURCE UTILIZATION

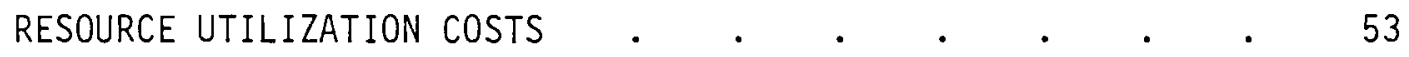

SOURCE ENERGY ACCOUNTING (ENERGY ANALYSIS) • • • • • $\quad$ • 55

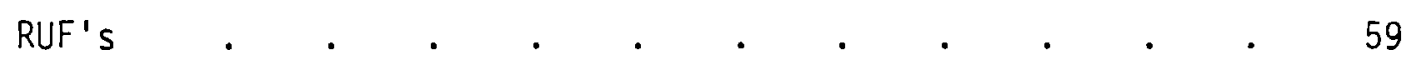

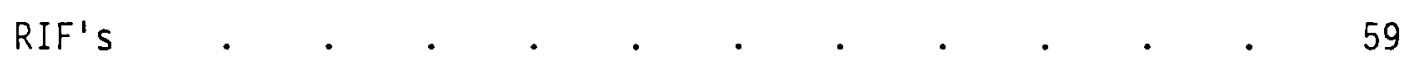

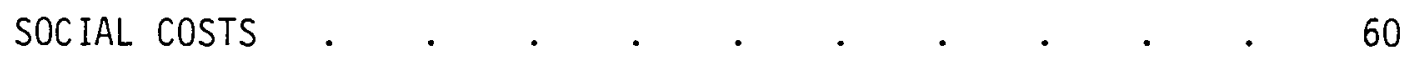

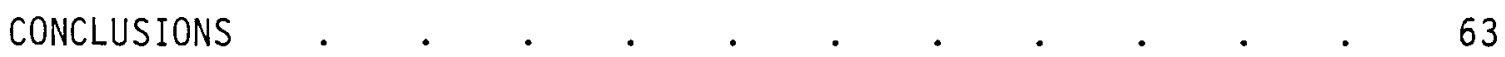

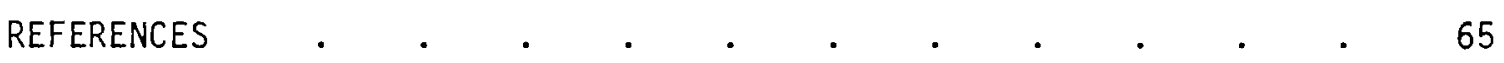

APPENDIX A - ANNOTATED BIBLIOGRAPHY $. \quad . \quad$. . . . . . A.1 


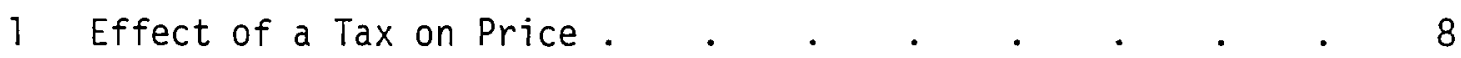

2 Social Costs of Energy Sources. . . . . . . . . 11

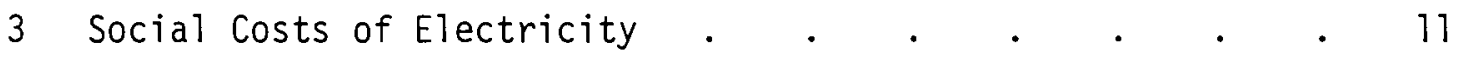

4 Annual Occupational Injuries in the Alternative Energy Systems . . . . . . . . . . . . 43

5 Design Energy Budget Derivation from the Life Cycle Model . 47

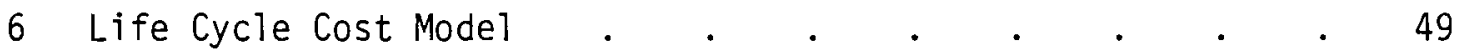

7 Components of Social Cost. . . . . . . . . . 54

8 Schematic of a Fuel Cycle (Energy Production System) . $\quad 54$

9 Relative Internalization of Damage Costs by Producers . . 55

10 A Generic End Use - Supply Trajectory for Energy Analysis . 56

11 Aggregation of Social Cost per End Use Btu . . . . . 61

\section{$\underline{\text { TABLES }}$}

1 Annual Costs of Federal Energy Regulation . . . . 25

2 Selected Deregulation Studies Examined by the FPC . . . 32

3 Federal Power Commission Marginal Supply Price

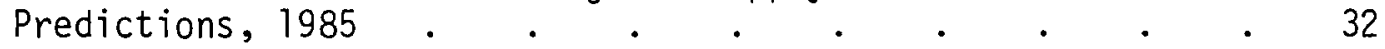

4 Comparison of RUF and RIF Conceptualizations . . . 60 


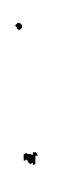




\section{INTRODUCTION}

The promulgation of building energy standards has been proposed by congress as a means of engendering conservation of energy resources. The decision to promulgate building energy standards implies that some form of market failure is leading to building design decisions that allocate resources suboptimaliy. When markets are allocating goods efficientiy, private investment decisions serve the public interest and government intervention is unnecessary. However, when individuals and firms receive incorrect price signals, are faced with monopoly power or inordinately high costs of obtaining information, the private costs of an activity do not capture the true costs to society of that activity. When the transaction costs associated with the policy option of correcting the prices consumers face are extremely high, as they are in the case of fuel prices, the less desirable policy option of setting a standard may be justified to decrease social costs.

In order to increase the welfare of society through the implementation of a building energy performance standard, a method is required by which the least cost means of obtaining the desired space conditioning of a building can be estimated. In other words, a life cycle cost model must be developed to simulate the energy related building design decisions that would take place if resources were being allocated efficiently. The cost minimizing model must incorporate technically efficient conservation strategies and fuel conversion equipment and the prices used must reflect the social value of the fuels and capital equipment used.

This report explores the feasibility of developing a factor that could be used to adjust a design energy budget to account for the external costs associated with that energy consumption. One such factor, RIF (resource impact factor) has been proposed by the American Society of Heating, Refrigerating and Air Conditioning Engineers (ASHRAE). Though ASHRAE suggested the RIF $\times$ RUF (resource utilization factor) ${ }^{(a)}$ multiplier concept, RIF's were not explicitly

(a) RUF's are multipliers accounting for quantities of energy resources consumed. They are developed in ASHRAE Standard 90-75R. 
defined. Weber (1978) suggested that Rif be defined as a ratio of social cost to effective market price. The basis for a RIF used in conjunction with a RUF is evaluated here and is found lacking.

To fill the gap, a social cost approach is developed which addresses the goals of both RIF's and RUF's. The rationale for using such an approach stems from the existence of differences between retail prices and the actual social costs of fuels.

\section{OBJECTIVES}

This study seeks to:

- Evaluate the effects and feasibility of using 1) life cycle cost criteria that incorporate social costs and discount rates and 2) a formula using RUF's and RIF's.

- Document the differences between market prices and total social costs in the fuel markets that are most closely related to building energy system design choices.

- Develop a method of accounting for both fuel resource losses and external costs of fuel use.

\section{APPROACH}

To evaluate the use of RIF's in building energy standards we first look at the problem RIF's were proposed to address. We examine each of the fuel markets for evidence that the market price of each fuel fails to reflect its true value to society. Components of the nonmarket portion of social cost are identified for each fuel and techniques for quantification of these costs are discussed. Then studies that provide empirical estimates of nonmarket costs for each fuel are summarized. This review of the literature provides evidence of the existence of differences between fuel market prices and actual costs to society during the past 15 years. These studies treat many causes of price distortion including monopoly, regulation, taxes, subsidies, and externalities including pollution and health effects. 
Following the exploration of differences between fuel prices and the total social cost of fuel use, a framework is developed to incorporate both social costs and energy resource losses into the setting of design energy budgets. The conceptual basis for RIF's and RUF's is discussed as are some of the problems in developing values. A theoretical model is then proposed that incorporates the essence of the RIF and RUF concepts in adjusted fuel prices which are then used in a life cycle cost minimization framework. 



\section{FUEL MARKETS AND SOCIAL WELFARE}

Behind the ASHRAE proposal that RIF's and RUF's be used in determining the choice of fuel in new buildings, there lies an assumption that for some reason or reasons the present market system does not promote optimal choices of energy resources. While many markets may deviate from the ideal, prices in fuel markets are assumed to be such poor indicators of fuel value to society that they should not be allowed to determine fuel consumption choices. The proposed incorporation of RIF's and RUF's also implies that society will be better off minimizing consumption of Btu than minimizing costs.

Ideally, markets function in a manner that leads to the production and distribution of goods and services in the quantities desired by society. Market prices of goods are determined by the interaction of the costs of production and the strength of demand for the product. Through a well-functioning market, consumers can get the largest quantity of goods at the lowest cost possible, thus maximizing the overall standard of living.

While perfectly free and competitive markets do not actually exist, the markets for many, if not most, goods and services generate prices which act to balance supply and demand relatively well. In markets that are functioning relatively well the price of a good approximates the value of that good to consumers, relative to the value of substitutes which they could have purchased. At the same time, the price represents the value in alternative uses of those resources used to produce the good.

To help explain the causes of failure in the fuel market, the following paragraphs describe situations that result in price distortion.

\section{CAUSES OF MARKET FAILURE}

A variety of problems can develop that prevent markets from allocating resources optimally. Given the existence of any of these problems in fuel markets, price can no longer be considered a reliable measure of either the cost to society of producing an additional unit of a fuel or the value of an additional unit to consumers. The result of such market failure is commonly referred to as price distortion. This section will examine major sources of 
price distortion, discussing the impact on prices of each in turn as though it were the only source of distortion. A market may be characterized by more than one of these problems, in which case the net effect is not easily disaggregated.

Because fuels are substitutes to some degree, fuel prices are interrelated and distortion in one fuel price affects other fuel prices as well. Thus, if natural gas is priced at significantiy less than its social cost, the price consumers are willing to pay for any fuel that is substitutable for natural gas will also be affected. If all fuels were priced at their social marginal cost, this price distorting effect would be eliminated. The causes of price distortion in fuel markets and the direction of their effects on prices are discussed below.

Monopoly

Competitive firms that take the price of their product as a given will tend to increase production until the cost, including normal profit, of producing another unit (marginal cost) equals the market price. However, many firms have monopolistic tendencies and are not passive price takers. In fuel markets, the OPEC Cartel has proved a prime example of this phenomenon. Due to one or more factors such as ownership of scarce resources, price fixing arrangements with other firms, dominant market shares, government 1 icensing or a large cost advantage, a firm may have flexibility in setting the price of its product. The resultant price will be higher than the firm's production costs including normal profit.

The monopolist's price then is an inaccurate indicator of the marginal costs to society of the resources used to produce products. The amount of price distortion associated with monopoly varies with the level of production but is equal to the difference between product price and the marginal cost of producing another unit. Monopoly power generally results in lower production levels and higher market prices than would occur if the product were competitively priced at close to its marginal cost.

\section{Externalities}

Price distortions may also be caused by spillover effects in production or consumption, called externalities. Externalities are said to exist when the 
consumption or production of one party affects the productivity or welfare of another party and no compensation is paid for the "external" benefit or cost. For example, the cost to a utility of buying coal and producing electricity may not fully account for the value of the environmental quality society is giving up by producing the electricity. In addition to the utility's actual expenses, all associated reductions in environmental quality and damage to life and limb must be considered "costs" to society. When these costs are summed, the market price of electricity produced from coal is found to account for less than the total value of the resources society is giving up to gain that production. As a result there may be more use of coal for electricity generation than there would be if market price equaled social cost.

\section{Price Controls and Regulation}

While price controls and regulation have been instituted in fuel markets to control distortions (monopoly pricing, for example), regulation can introduce price distortions of its own. In seeking to eliminate a high monopoly price, the government price controls may inadvertantly be set too low. Both monopolistic and regulated pricing have the common effect of reducing output. However, monopolistic pricing discourages consumption, while price controls discourage production. If the price set is lower than the value of an additional unit of the good, consumers react to the low prices by attempting to purchase additional amounts while the suppliers simultaneously reduce production quantities. Thus price controls usually result in a shortage as has been the case for natural gas.

Taxes and Subsidies

Sales taxes cause a divergence between the price paid for a good or service and the amount for which the seller can produce the item. The amount of tax separates the value of the product to consumers from the social cost of producing it as illustrated in Figure 1. The supply curve represents the cost to society of producing another unit of the product. Without the tax the price will be $P_{1}$ with a quantity of $Q_{1}$ purchased. In this case the price accurately reflects the value of alternatives given up when the good is produced. A per unit tax $\left(P_{2}-P_{3}\right)$ will raise the price to consumers to $P_{2}$ but lower the price received by the seller to $P_{3}$. As a result the value of another unit to the 
consumer $\left(P_{2}\right)$ is greater than the value of the resources used to produce this product $\left(P_{3}\right)$. Subsidies have the opposite effect. They can be seen as negative taxes resulting in product prices that are lower than the cost of production. Quantities consumed then exceed the quantity at which the value of the product to consumers equals the value of the resources consumed in alternative uses.

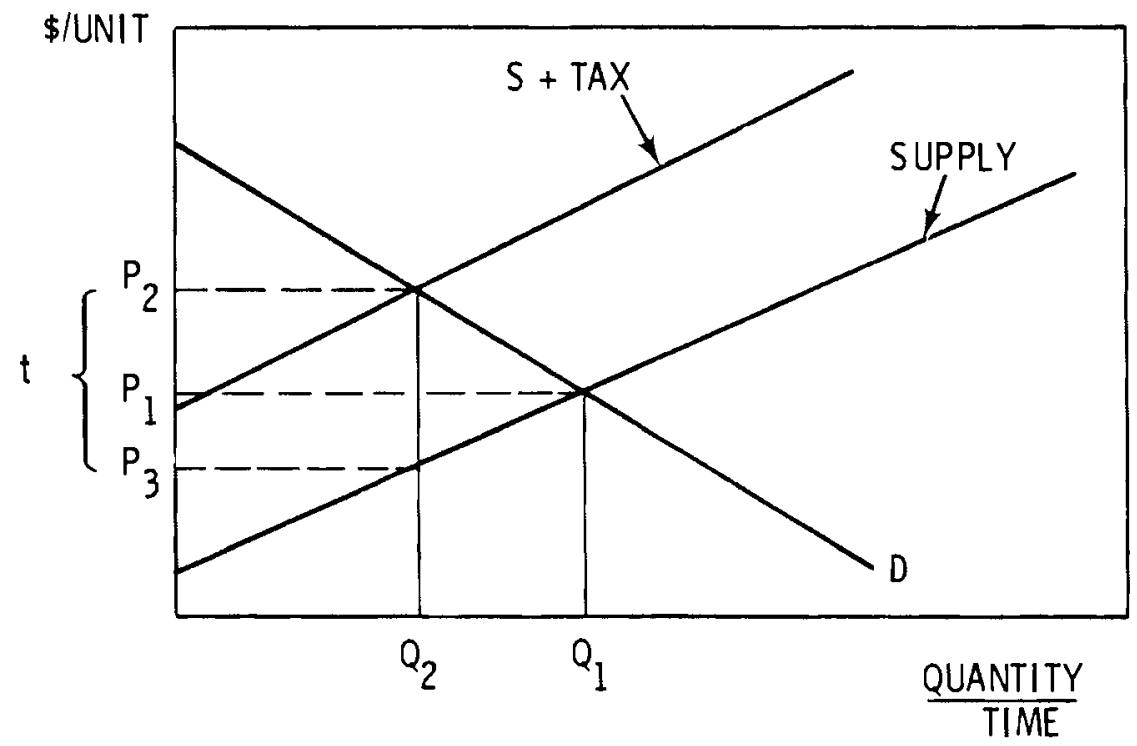

FIGURE 1. Effect of a Tax on Price

In addition to sales taxes, income taxes affect fuel markets. Current corporate income tax regulations encourage the substition of energy expense for capital investment in building conditioning systems. This is because all of the costs of fuel may be expensed in the year paid, but the allowable depreciation rate for buildings does not keep pace with the normal rate of payment for such capital investment. Thus the tax structure induces more fuel consumption than would otherwise take place.

\section{THE "SECOND BEST" PROBLEM}

In markets where social cost and price differ it is difficult to know whether changes due to any given policy result in an improvement in social welfare. This situation is explained by economists in the "general theory of second best". According to this theory, when one of the conditions necessary 
for optimal resource allocation is unattainable, attaining the other conditions is generally undesirable (Lipsey and Lancaster, 1956-57). This would seem to indicate that the use of social costs to allocate resources in space-heating fuel markets is undesirable when decisions in other markets are based on distorted fuel prices. However, it can be shown that when a constraint, such as price distortion, is removed and the result is increased efficiency in production, welfare is improved by removing the constraint. Hence the correction of fuel price distortions is justified since comfort levels in space heating can be maintained while the total value of the resources consumed is reduced.

\section{COMPARISON OF EFFICIENCY CRITERIA}

While efficiency is considered a desirable goal by most people involved with energy policy issues, concensus is lacking on whether thermal efficiency, economic efficiency or some combination of the two should be the controlling criterion for energy-related decisions. A widely used definition of thermal efficiency is:

Thermal efficiency $=\frac{\text { useful work done }}{\text { energy input }}$

Unfortunately, if thermal efficiency is the only criterion used to determine energy system investments, the results will conflict with other desirable goals. The following example illustrates the type of undesirable resource allocation that may result from the use of energy efficiency to set energy consumption standards.

Imagine our task is to build an "energy efficient" house, based on measurements of thermal efficiency. We have two possible extremes in trading off the initial investment and fuel consumption of a building:

Method I: Use large amounts of insulation, the most efficient furnace available and minimal quantities of fuel.

Method II: Use minimal amounts of insulation, a relatively inefficient furnace and large amounts of heating fuel.

A comparison of the thermal efficiency of the two systems would find Method I a more "efficient" method of space heating. However, if the insulation material had some valuable alternative use for which it had few good 
substitutes and an abundant, low-cost resource was used as the heating fuel, the use of thermal efficiency as a design criterion would seriously misallocate resources. Using the more energy efficient Method I means conserving fuel while "wasting" another valuable resource. Though energy conservation is an important goal, it is clear that thermal efficiency ratios alone are not particularly good criteria for determination of building energy consumption levels.

A major problem with using energy efficiency ratios to select the best energy system design is that such ratios fail to account for the relative values of the resources used. The concept of efficiency used in economics directly addresses the problem of valuing the alternative resource uses. Economic efficiency may be defined as:

Economic efficiency $=\frac{\text { value of output }}{\text { value of input }}$

If two alternative methods produce exactly the same output and thus the same value of output, we can compare their relative efficiency on the basis of the value of the inputs. The method that produces the desired output at the lowest input cost is the most efficient. Conversely, for two processes with inputs of equal value, the more efficient process will be the one with the highest valued output. The economic efficiency criterion allocates resources in a manner which maximizes the difference between benefits and costs.

\section{SOCIAL COST MODELS}

The cost components that compose the total cost to society of energy sources used in building space conditioning are illustrated in Figure 2 . In particular, the aggregation of social costs for fuels used in generating electricity is shown in Figure 3 . The nonmarket costs referred to are all those costs resulting from fuel production and consumption that are not included in the price charged by the producer or paid by the consumer. It should be noted that in developing the social cost model for electricity, only the nonmarket cost portions of the social costs of gas and oil are incorporated. This is done because the market cost of the oil and gas inputs to electricity is included in the market price charged for electricity by the utilities. 


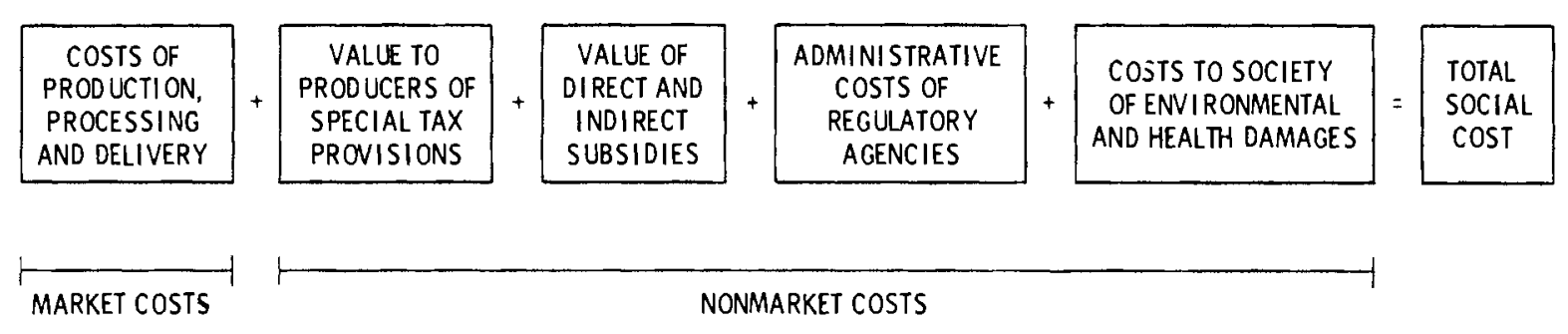

FIGURE 2. Social Costs of Energy Sources

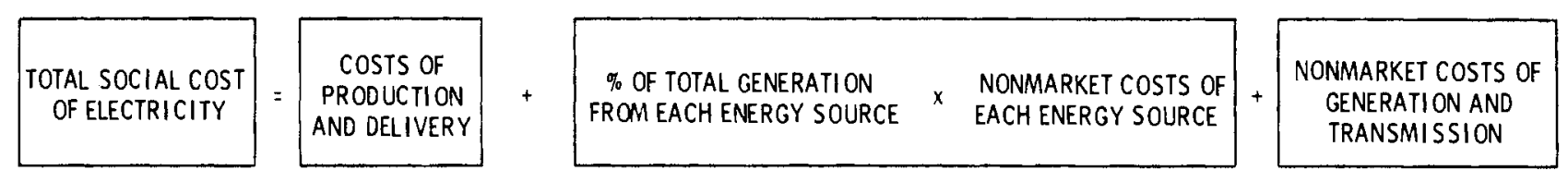

\section{FIGURE 3. Social costs of Electricity}

In estimating the full social cost of fuel use, the external costs and the market price are summed to account for both public and private costs. Since the final use of these estimates is to determine the fuel consumption levels in new buildings, the private costs should be approximated through use of the marginal cost of fuel supplies for new users. The marginal cost is appropriate because it reflects the cost to society of expanding fuel supplies. Both marginal costs and sources of new supply will vary from region to region. The cost of LNG is the relevant marginal cost of gas in some regions; SNG represents marginal cost in others. For oil the appropriate figure is the world oil price. The marginal cost of electricity is most difficult to estimate since the marginal source of supply for building space conditioning may not only vary from region to region but also may vary seasonally within regions.

Methods of estimating social costs are presented in the next section. Each block shown in Figures 2 and 3 is composed of many factors; some techniques for identifying the cost associated with each factor are described. 


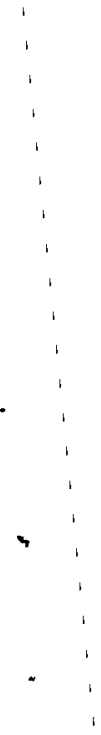




\section{SOCIAL COST ESTIMATION TECHNIQUES}

In order to make design choices that utilize fuel and other resources efficiently, the relative social cost of each resource must first be known. Various techniques have been developed to estimate the social marginal cost of producing goods. These techniques can also be used to estimate the value to society of losses resulting from distortion between market prices and social marginal cost. Nearly all of these techniques, however, have deficiencies which prevent precise and reliable dollar estimates of social cost. For example:

1. The estimation of social marginal costs entails discovering the total cost to society of producing an additional unit of some product. The total cost includes not only the marginal cost of production for that unit but also the marginal cost of environmental damage resulting from its production. Due to data problems, most empirical studies provide estimates of average cost rather than marginal cost of environmental damage. While these estimates may provide a good indication that social costs exceed market price, use of average costs as a basis for social cost estimates may either overstate or understate the value of social marginal costs.

2. Externality costs are associated with nonmarketed goods such as air quality and beautiful scenery. Estimating these costs requires indirect measurement techniques to value the marginal cost or benefit. For example, the siting of a cooling tower for a power plant will reduce the aesthetic appeal of the area - a social cost - but without a direct market price for aesthetic appeal we must rely on inferential estimating techniques.

3. Estimating the impacts of taxation, monopoly and market regulation necessitates estimating the amount of deviation from the situation that would exist without these sources of price distortion. Since many of these factors have been in existence for a long time, precise and accurate estimation of what today's market price would be is impossible. Similarly, it is difficult to determine the direction and extent of error in estimates of distortion-free market prices since the true social costs remain unknown. 
4. Social costs of fuel production depend on the technology used in production, the timing and location of production as well as a host of other variables. The social marginal cost of producing coal in one area of the country differs from the cost in other areas because of the use of different technologies, and because different populations and ecological systems are affected. Sound estimates of social cost must include consideration of the variability of these important factors across the United States. While these problems mean the estimation of social cost is an inexact science, the estimates are useful in a variety of ways. They can provide a good indication of the relative costs to society of alternative fuel uses. The relative degree of price distortion for substitute fuels can also become apparent from social cost estimates. In addition, defensible minimum estimates of the social costs of fuel production can provide a basis for improving policy related to resource allocation.

The most promising methodology for estimating the total social marginal cost of fuel production involves estimating price distortion for each of the relevant cost components independently and summing these to obtain an estimate of the total price distortion. Adding this estimate to the market price (marginal cost of new fuel supplies) provides an estimate of total social marginal costs. Estimation techniques appropriate for each of the social cost components for fuels, including externalities, monopoly, regulations, price controls, subsidies and taxation, are discussed in the following sections.

Though it is desirable to estimate the marginal social cost of fuel production, at the present time the available methods and data do not allow this. In most cases it is only feasible to estimate average social cost for the quantity of fuel currently produced, rather than marginal cost. If, as is likely, the average cost per fuel unit is less than the marginal cost per unit, the methods discussed below can be used to derive a minimum estimate of marginal social cost for the quantities of fuels currently produced. 


\section{ESTIMATION METHODS FOR EXTERNAL COSTS}

As pointed out previously, externalities cause a gap between the market price of a commodity and the value of that commodity to society. The value of an externality can be measured both through observation of behavior and direct inquiries regarding behavioral intentions.

\section{Observed Behavior}

Two main approaches to valuing externalities which depend on observations of behavior are examination of property values and assessment of alternative costs.

\section{Property Value Approach}

Changes in individual behavior caused by a change in the amount of an externality are often reflected in property values. Consider, for example, a homeowner living downwind from a nearby paper mill. If the mill was forced to shut down or reduce its release of malodorous gases the value of the homeowner's property would rise relative to other housing farther from the mill. Under a set of rather restrictive assumptions the aggregate change in property values associated with a change in the level of an externality can be used as a proxy for the benefit or cost of the change.

\section{Alternative Cost Approach}

This approach uses the additional expenditures an individual incurs as a result of an externality to estimate the value of the externality. For example, a change in the level of air pollution may increase the rate of exterior paint deterioration. The additional paint and labor expenditures which result from an increased deterioration rate are taken by this approach as a measure of the cost of the increase in air pollution. Studies using this approach typically underestimate the value of an externality because less easily quantified impacts, such as health effects, are excluded from consideration.

\section{Direct Inquiries}

Direct inquiry uses an individual's statement of his/her past behavior or behavioral intentions to estimate the value of an externality. Two approaches, the demand and direct-bid, which use inquiries, are described as follows. 


\section{Utility-Demand Approach}

This approach uses responses to a series of questions to measure the satisfaction (dissatisfaction) or utility (disutility) an individual derives from being exposed to an externality. This information is used to derive a demand curve for the externality based on microeconomic theory. Individual demand curves are then aggregated to form a market demand curve from which the benefits and costs associated with changing the amount of the externality can be derived. It has been argued in the economics literature, however, that the use of demand curves is inappropriate for valuing externalities, since small units of an externality cannot be purchased. Following this reasoning, a demand curve, which is simply willingness to pay for additional units of a good, is an inappropriate measure for valuing externalities.

\section{Direct-Bid Approach}

The direct-bid approach directly asks individuals their willingness to pay and their willingness to accept compensation for externality level changes. These measures are then used to construct aggregate estimates of the value of an externality. This approach, while sound in theory, has the drawback of being a form of "game" which may not accurately reflect behavior.

Critique of Externality Valuing Methods

Most of the methods discussed above can provide reasonable estimates of the value of an externality given certain assumptions. The methods using observed behavior typically require strict theoretical assumptions which are often unrealistic. Yet these methods have the advantage of using relatively low cost secondary data to derive estimates.

The methods using direct inquires are "sound" in terms of economic theory. They are extremely flexible and as a result can be used for the valuation of a wide range of existing and potential externalities. They do, however, require primary data collection which is more costly than using secondary data. In addition, estimates are based on a hypothetical situation in which an individual is not actually required to behaviorally validate his/her statements by paying or accepting compensation. 
Typically, budget constraints have forced the use of observed behavior methods in previous work on valuing externalities. In recent years, however, the expected additional benefits associated with the direct inquiry approaches have stimulated their increased use.

\section{METHODS OF ESTIMATING PRICE DISTORTION FROM MONOPOLY}

The monopolist's behavior causes prices to be higher and output quantities lower than would occur under free market conditions. While we can observe the price and the quantity sold by a monopolist's firm we usually cannot obtain information on the marginal cost to the firm of producing another unit. This information is needed to find the difference between monopoly price and the marginal cost of the resources used.

Use of Average Costs as a Proxy for Unknown Marginal Costs

Accounting statements of a firm may be used to estimate average costs of production. The direction of the difference between average and marginal costs is unknown since the average cost of production could either be higher or lower than the marginal cost of producing another unit. If, however, average costs are constant over the range of quantities produced, the marginal cost of producing another unit will equal the average cost. Empirical evidence indicates that this is true of many firms. In this case accounting costs may provide a reasonable basis for estimating the price distortion due to monopoly power. Use of Profit Rates

Profit rates have been used both as an indicator that monopoly exists and as a measurement of the distortion. Both can be inappropriate applications. While a monopolistic firm's profits may be excessively large, they are not always so. For example, when a monopolistic firm changes hands the price may reflect high expected future product prices. Then the buyer of the firm will find himself earning a "normal" rate of return on investment. Thus, monopolistic pricing may exist without high profit rates.

Use of Industry Concentration Ratios

While the industry concentration ratio is not used to measure price distortion, it is commonly used as an indicator of possible monopoly pricing. The 
concentration ratio measures the percent of industry sales (or other variables) associated with the industry's largest firms. While the theory linking concentration ratios and monopoly pricing is not perfect, it is the most commonly accepted tool for identifying industries in which there may be monopoly pricing. Concentration ratios coupled with profit investigations of the type used by Worcester (1973) or Harberger (1954) could give reasonably defensible estimates of monopoly pricing distortions.

\section{ESTIMATION OF PRICE DISTORTION DUE TO REGULATION}

Price regulation has generally taken the form of setting price ceilings and it assumes the prior existence of monopolistic pricing in an industry. In spite of its purpose, much of the present government regulation of industry does not appear to push prices toward competitive market levels, but rather serves to protect producers. By restricting price cutting and inadvertently preventing entry to the industry, monopoly power for existing firms may result from regulation. There is evidence both of prices being both higher and lower than the market clearing price in different regulated fuel markets.

Accounting Data

Since regulated firms are required to provide cost data at rate hearings, accounting information is readily available for regulated firms. Often average variable costs taken from the accounting data are used as a proxy for marginal costs to estimate the difference between monopoly price and marginal cost. However, a serious difficulty with the use of accounting data emerges when regulation confers a monopoly position on a firm such as a regional utility. That firm has an incentive to devote resources to maintaining and increasing its monopoly profits. This will lead to added costs, such as lobbying expenses, to protect its regulated position. In this case, use of accounting data to estimate the price distortion is misleading, since though price will be higher than a competitive level, costs will tend to increase over time until the pricecost margin is about the same as for an unregulated firm.

An example of cost increases associated with regulation is found in the competition for customers that occurred in the airline industry as a result of 
the protection from entry of new firms and restriction on price cutting by the Civil Aeronautics Board. Airlines attempted to win passengers by competing in service quality; as a result profits have often been low because costs increased until excess profits were dissipated.

Econometric Modeling

Econometric modeling allows the researcher to estimate the underlying supply and demand curves considering not only the interrelationships between price, quantity demanded and quantity supplied but also other variables influencing supply and demand. Simulations are performed to predict the equilibrium price in the absence of regulation. The main advantage of this method is its ability to consider a variety of variables and their effects. For example, removal of price controls will lead to a price increase but this higher price may increase the quantity supplied which in turn reduces the shortage. The magnitude of these effects can be examined with econometric models which capture the structure of supply and demand.

Unfortunately, the complexity required in the model leaves some room for error. Including variables that do not belong or excluding relevant variables both create statistical problems, as does moving into multi-equation, multi-time period specifications. Even more serious problems may result from using a model based on past data to predict outside the range of that data. This is particularly important for fuel markets since prices may change drastically as we move from a regulated to a deregulated market. In spite of these problems, a carefully developed econometric model, tested and corrected over time, probably provides the best method of estimating price distortions.

\section{Comparison With Unregulated Prices}

A method commonly used in estimating the extent of price distortion is to compare the regulated price with the price of a similar unregulated product. For example, a rough estimate of the unregulated price of natural gas could come from either the unregulated price of gas in intrastate sales or the price of imported gas. While this method has advantages in terms of minimal cost of arriving at a value, theoretical problems indicate that these comparisons produce poor estimates of the true unregulated price. In the case of natural 
gas, the supplies of gas diverted to intrastate sales are probably higher than would be the case without regulation and the price is probably lower. Similarly, the price of natural gas from other countries provides an estimate of what a customer, unable to obtain gas at the lower regulated price, would be willing to pay to obtain any gas at all. This is higher than the probable deregulated price under which producers would respond with additional supplies, making likely a lower unregulated price than the price of foreign supplies.

\section{METHODS OF ESTIMATING PRICE DISTORTION DUE TO TAXATION AND SUBSIDY}

While taxation and subsidies may create the greatest price distortions, few estimation techniques have been developed to actually measure the net effect for particular products.

As was graphically shown in Figure 1 , if $P_{1}$ were the price of the product before a tax of $t \$$ /unit is applied, $P_{2}$ will become the price paid by the consumer, $\mathrm{P}_{3}$ the price received by the supplier. The difference is the tax. Note that the effect of the tax is to increase the price to the consumer and decrease the price to the supplier. Only under unusual circumstances will there not be some splitting of the price change between consumers and producers due to imposition of a tax.

In a world with numerous taxes and special tax provisions, analyzing the net distortion from all taxes affecting a particular product is probabiy an impossible task. Analyzing the net effect of a special tax appears to hold more promise. Some models have been developed to predict the effects of a tax on product price. However, analysis of the myriad of special tax provisions for fuels and energy would require a great deal of additional work before the total distortion could be calculated.

Alternatives are to simply calculate the dollar value of a tax or subsidy, average this over the product units produced and assume the price has been distorted by that amount. While this estimates the price distortion for a given quantity of the product, it is inaccurate if the per unit level of taxation or subsidy or the product quantity changes. 


\section{EMPIRICAL ESTIMATES OF SOCIAL COSTS}

Estimates of the unpriced social costs associated with fuel usage have been developed by a wide variety of governmental and private sources. Estimates of the major social cost components for oil, gas and electricity are discussed in the following subsections. Because these estimates were derived for different purposes and cover a period of fifteen years, the figures quoted cannot be used as estimates of current social costs. They do, however, provide a starting point for derivation of current and consistent estimates. Brief summaries of some sources of social cost estimates are included in the Appendix.

$\underline{O I L}$

Most Americans probably consider the energy crisis to be an oil crisis. Indeed, the shortages and price increases of the past few years have created the feeling that independence from foreign supplies is an important policy objective. The concern may be well founded. Domestic petroleum production fell over 13 percent from 1970 to 1975, a time when 011 consumption was growing (U.S. Bureau of the Census 1976, pp. 548-549). The OPEC price increase occurred during this period as did the institution of a multitude of government regulations and tax changes.

This section attempts to analyze a variety of studies dealing with estimation of oil price distortions. Monopoly will be examined as a potential cause of prices that are higher than social cost. Regulations are evaluated in terms of their potential for creating either monopoly-like results or controlled prices that are lower than social cost. An attempt is made to provide estimates of the effects of the special tax provisions for oil in the section on taxation and subsidies. In addition, externalities are examined and in particular national independence is viewed as a form of externality where the price to the individual of additional oil consumption is below the value of what society gives up because of that consumption.

Monopoly

Fears of monopoly in the oil industry have been greatly exacerbated by the events of the past few years. Large price increases, product shortages, movement of major oil companies into the production of alternative energy sources 
and the sheer size of many integrated oil producers have served to convince many that monopoly pricing exists in the production and distribution of $0 i 1$. Congress, the Federal Trade Commission and numerous public interest groups have investigated the oil industry to a degree probably unprecedented in American business history. (a)

While recognizing the problems with firms large enough to influence government policy, most economists have concluded the oil industry to be workably competitive. In a study of competition in the oil industry, Thomas Duchesneau (1975, pp. 38, 44) found market concentration ratios of 32.9 percent for domestic refining and 30.5 percent for crude $0 i 1$ production. The largest firm involved in domestic refining contributes only 9.1 percent to total sales while the largest firm in crude oil production contributes 10.7 percent. While the size of these oil companies is large relative to the average U.S. manufacturing firm, the industry does not appear to be dominated by one or even a small group of firms. Structuraliy the oil industry does not appear to be much different from most U.S. manufacturing industries.

Firm and industry performance can also help to indicate the presence of monopoly. Accounting profits reveal that oil firms have not been especially profitable in the past fifteen years. There has been little difference between profit rates for petroleum firms and manufacturing as a whole. Shyam Sunder's analysis of the risk adjusted returns reveals investors in petroleum were slightly better off than the level of returns for all New York Stock Exchange firms, but he attributed this to a slight improvement in the future prospects of the industry (Sunder 1977).

A study of monopoly based on profit data by Dean A. Worcester, Jr. (1973) identified 30 firms out of over 500 as potential monopolists. Only one of these was an oil industry firm, Commonwealth $0 i 1$, but that firm was hardly a major producer. Of 859 companies ranked by Forbes Magazine (1975) according to return on equity over a five-year period, none of the largest eight $0 i 1$ companies were in the top 100 . The mean location was 297 th with a number of

(a) See U.S. Senate Committee on the Judiciary 1973, U.S. Senate Committee on the Judiciary 1975, Federal Trade Commission 1973 and Green 1972. 
small oil companies ranked higher than the industry giants. Most of studies are consistent with the conclusion that workable competition exists in the oil industry.

Regulation

Regulation of the oil industry has served a variety of interests. Walter Mead, a noted natural resources economist, identifies four types of petroleum supply restrictions (Mead 1976, p. 130).

1. Regulations designed to benefit the petroleum industry. This includes import quotas, and regulations that limit output and increase prices.

2. Regulations that benefit society including the petroleum industry. These include restrictions that reduce externalities and too rapid exhaustion of $0 i 1$ resevoirs, e.g., unitization and prorationing of the Maximum Efficient Rate type.

3. Regulations designed to protect society's interests that may (or may not) benefit the industry. Examples include environmental protection and health and safety laws.

4. Regulations designed to benefit consumers at the expense of the oil industry. Price controls, compulsory allocations and entitlements fit into this category.

Several of these categories of regulations create pricing distortions in the oil industry; others act to correct existing problems. The first category increases the price of $0 i 1$ as would a private monopoly or cartel. If monopoly is not a significant problem, the last of these categories also causes a distortion. Categories (2) and (3) are designed to reduce or avoid distortions that would otherwise exist.

Initially, regulation of the petroleum industry established a system of property rights in a chaotic industry ruled by the law of capture. Given the migratory nature of $0 i 1$ and the legal interpretation of ownership accruing to the individual who could "capture" the oil, these rules were designed to prevent too rapid exhaustion of a reservoir. However, the outcome of the regulations was a system of limiting production which more closely approximated a cartel price fixing arrangement than a practice to conserve resources. 
In addition to establishing a cartel-like price, the early regulations had the effect of raising average costs for the industry by allocating high production levels to high cost producers. A 1961 estimate of the size of this distortion was $\$ 0.80$ to $\$ 1.00$ a barrel, approximately 40 to 50 percent of the price of crude (Ade1man 1964, pp. 101-124).

From 1959 to 1973 the United States operated a quota system to restrict the quantity of imported 011 . By restricting foreign competition through the mandatory oil import program, the domestic price of oil was increased. Estimates of the cost to consumers have been placed at around $\$ 6$ billion for 1969 (Mitche11 1974). (a) This represented about two dollars a barrel.

Production restraints and the mandatory $0 i 1$ imports program have been replaced by a regulatory framework designed to respond to the Arab oil embargo of 1973. These regulations have changed almost yearly but are designed to moderate the effects of high OPEC prices on domestic prices, while simultaneously protecting small and independent operators in the petroleum business.

At least one study, by James C. Cox and Arthur W. Wright (1978), indicates the government program has achieved some success in keeping the price of domestic oil below the world market price. Their study does not attempt to quantify the difference but concludes that the controls have increased the domestic supply of refined products and lowered retail product prices. The objective of the Cox and Wright study was to analyze the direct and short-term effects of the current regulatory program. Ignored are the increased costs of compliance, the effects of artificially encouraging small (possibly inefficiently small) refineries and the long term effects that price controls and regulations would have on investment and future supplies. These controls could create shortages if the retail price level of consumer products is set too low and higher prices could result in the long term if firms display reluctance to invest in an industry with an uncertain regulatory future.

The Presidential Task Force on Federal Energy Administration Regulation has estimated the annual costs of present regulations. They identify the

(a) Mitchel1 quotes Burrows and Domenich 1970, and the Cabinet Task Force on $0 i 1$ Import Control 1970. 
costs of compliance borne by oil company stockholders and customers through higher prices, government administrative costs borne by taxpayers and the subsidy to small oil producers. Table 1 provides estimates of these costs.

\section{TABLE 1. Annual Costs of Federal Energy Regulation}

\begin{tabular}{lc}
\multicolumn{1}{c}{ Source of Cost } & $\begin{array}{c}\text { Annual Amount } \\
\text { (millions of dollars) }\end{array}$ \\
\hline Subsidy to small refiners & 400 \\
Program administration & 500 \\
Compliance costs & $\frac{570}{1,470}$ \\
Total &
\end{tabular}

Source: MacAvoy 1977, pp. 143-145.

Studies indicate present oil prices under the Energy Policy and Conservation Act may be temporily lowered, possibly resulting in increased future prices due to inefficient production units. Attempting to evaluate the effects of a changing, far-reaching regulatory program is a difficult problem. Much more research would be required to obtain a sound and comprehensive estimate of the magnitude of distortions from oil industry regulation.

Taxation and Subsidies

Taxation of income from the oil industry has historically been subject to a variety of special provisions and treatments. In addition, the costs of numerous government programs designed to encourage exploration, production and safe transportation of oil products have been borne by U.S. taxpayers. This section attempts to describe and quantify the effects of these incentives as they existed. Within the past few years, major changes in U.S. tax laws have served to reduce their distorting effects on oil prices.

The tax provision usually considered to have created the major taxrelated disturbance in $0 i 1$ prices is the depletion allowance. The effect of this provision was to provide a tax benefit by reducing taxable income. Studies indicate this provision provided a net benefit of about 15 percent 
of the gross income from crude oil production (Brannon 1974, p. 26). Converting this estimate of the benefits to the producer into an effect on prices requires assumptions about the behavior of $0 i 1$ producers. Assuming that competing producers were forced to pass along to consumers all savings from special taxation of $0 i 1$, estimates indicate a 13.2 percent reduction in price would result (Brannon 1974, p. 27). A similar estimate of 10 to 12 percent was obtained in a study which analyzed the size of the likely price increase from a partial elimination of the depletion allowance (McDonald 1976a).

Significant indirect subsidies have occured in several of the stages of oil marketing. 0il exploration efforts have benefited from the work of the U.S. Geological Survey. Transportation of 011 has indirectly benefited from the construction and maintenance of the inland waterways and coastal ports. In addition, transportation of oil has directly benefited from the Merchant Marine Act of 1970 which provides subsidies for the construction and operation of tankers operating under the U.S. flag (Cone et al. 1978, pp. 226-230). One estimate of this last subsidy was 175.5 million dollars in 1976 and the level of the subsidy has been increasing yearly ( $p .231$ ).

The oil depletion allowance has been significantly altered in the past few years. The Tax Reduction Act of 1975 effectively eliminates the percentage depletion for the major $0 i l$ and gas producers and significantly reduces it over the next few years for all others (McDonald 1976a, pp. 26-50, and 1976b). Before the removal of the depletion allowance, the total tax burden on $0 i 1$ companies was estimated to be about 25 percent less than the average for all U.S. manufacturing (Brannon 1974). While research on the magnitude of the effects of remaining special mineral provisions in the tax system would be necessary to estimate the present tax differential, it is no longer obvious that $0 i 1$ prices are more significantly distorted due to taxation than prices of other minerals or even possibly other manufactured products.

\section{Health Effects}

The health effects attributed to oil result primarily from combustion. Air pollutants emitted include sulfur dioxide, particulates, nitrogen oxides, trace metals and possibly carcinogenic hydrocarbons. On a 8 tu bas is the total quantities released are substantially lower than those released by combustion 
of coal. While the quantities of nitrogen oxides per Btu are about equal, oil produces only 25 percent of the sulfur dioxide and one percent of the particulates that result from combustion of coal. These latter three types of pollutants appear to be the major causes of health and environmental damages (U.S. AEC 1974).

Environmental Effects

Environmental damages stem from both transportation and combustion of 0il. In addition to impairment of health, sulfur dioxide damages plants and materials such as building surfaces. Costs resulting from some of these damages have been estimated using the property value method by Anderson and Crocker (1970) and using the alternative cost approach by Salmon (1970). Major environmental damages also result from oil spills during ocean-borne transport. These are most likely to occur near shorelines, with the resultant damage varying greatly depending on the location and circumstances of the spill. Presently there are only a few data points available for the estimation of $0 i 1$ spill costs and these range from $\$ .50$ to $\$ 14$ per gallon spilled (Environmental Protection Agency 1973).

Embargo Costs

The cost of an oil embargo is nearly impossible to measure due to its diverse and interrelated effects on society; however, estimates have been developed of the direct effect on GNP. One of these by Holcombe (1974) values the loss of production due to a complete embargo of Middle Eastern oil during 1980 at between $\$ 49$ and $\$ 117$ billion. These numbers are of questionable validity because of the age of the data used and the fact that only production losses are considered.

NATURAL GAS

Natural gas presently supplies 33 percent of the total energy consumed in the United States, (U.S. Bureau of the Census 1976, p. 547) forty-four percent of the nontransportation energy, (U.S. Federal Energy Administration 1976, p. 11) and 50 percent of residential energy consumption (Mitche11 1974, p. 63). One important reason for the attractiveness of natural gas is that it is probably the least environmentally damaging of the major fuels. 
An estimate indicated in 1970 that within the U.S. at least 1,200 tri1lion cubic feet of gas are recoverable at $\$ 0.70$ per thousand cubic feet (Garrett 1970). This supply will only last about fifty years at current consumption rates (Mitchell 1974, p. 24). In recent years, producers have been unwilling or unable to supply the quantities of natural gas desired by consumers at market prices. Much of the blame for this shortage must fall on a distorted market price; because it has been kept artificially low it has stimulated consumption while discouraging production.

In this section, several studies are analyzed which deal with the magnitude of price distortions for natural gas. While the effects of the Federal Power Commission's regulation of natural gas prices appear to overwhelm distortions from other causes, we shall mention the possible effects of taxation and subsidies and the possibility of monopoly pricing in the absence of regulation.

\section{Regulation}

The consistent shortages of natural gas experienced over the past several years indicate that price has not been allowed to function as a rationing device. At the regulated prices people desire to purchase more gas than producers are willing to supply. Future price increases can be expected to encourage some consumers to find substitutes for gas and some producers to supply additional amounts. In the case of natural gas, the price has been prevented from rising by a series of government interventions in the natural gas market.

The history of regulation of the natural gas industry is well documented. (a) The regulations had their origins in the Natural Gas Act of 1938, which placed pipelines under the FPC's regulatory authority. The wellinead price of natural gas was not initially regulated but was added to the FPC's jurisdiction by the Suprene Court decision in Phillips Petroleum Company vs. Wisconsin. After an

(a) See Breyer and MacAvoy 1974, pp. 72-75; Helms 1974; Kitch 1958, pp. 47-48; MacAvoy 1962; MacAvoy 1971; MacAvoy and Pindyck 1973; and Mitchel1 1974, pp. 57-58. 
initial attempt to set the wellhead price on a case-by-case basis and the deluge of paperwork which ensued, the regulators shifted to an area maximum price. In the 1970 s, this was changed to a national maximum price.

The effect of the pricing regulation was to freeze the price of gas at its late 1950s price. As the importance of incentives to induce exploration and production of additional gas was recognized, the FPC set up a dual system of prices. To prevent the realization of windfall profits, only the price of "new" gas was increased. These gradual price increases usually occurred in response to obvious shortage situations and prices did not keep pace with the general inflation rates of the 1960s and early 1970s nor with the increased prices of substitute fuels. The resultant shortages led to curtailment of services, diversion of gas to nonregulated customers (intrastate and some industrial buyers) and the introduction of higher-priced substitutes such as 1 iquefied natural gas.

The last few years have seen a dramatic increase in the maximum allowable wellhead price. In 1974, a nationwide price of $\$ 0.05$ per thousand cubic feet (Mcf) was instituted followed in 1976 by a price increase to $\$ 1.44$ per Mcf for newly discovered gas and an increase in the price of gas committed in sales under the lower tier of prices. Though the effects of previous price distortion are still apparent, the last round of price increases has significantly reduced the price distortion for natural gas. Indeed, the National Energy Act of 1978 provides for the removal of a major portion of price regulation of natural gas by 1985 .

\section{Econometric Models}

There have been numerous studies estimating the size of the price divergence due to regulation. Probably the best known is the series of econometric models developed by Paul MacAvoy and Robert S. Pindyck of the M.I.T. Energy Laboratory. Their basic model of the natural gas industry has been updated and improved several times. It has been published in a variety of sources and is accessible by computer. (a) Their current model probably represents the state-of-the-art for econometric modeling of the natural gas industry.

(a) See MacAvoy 1962; MacAvoy 1971; MacAvoy and Pindyck 1973; and MacAvoy and Pindyck 1975a and 1975b. 
Several econometric models of the natural gas industry have been compared by Robert Pindyck. In addition to the MacAvoy-Pindyck model, models from the work of J. D. Khazzoom (1971) and E. W. Erickson and R. M. Spann (1971) were reestimated over a consistent time period to compare results (Pindyck 1974). The MacAvoy-Pindyck model performs best of the three tested. Since this was an early version of the model, subsequent upgradings and improvements by MacAvoy and Pindyck have probably improved its performance relative to the other natural gas models.

An early version of the MacAvoy-Pindyck model (MacAvoy and Pindyck 1973, pp. 490-491) used cross sectional and time series data from 1964 to 1970 to estimate a system of supply and demand equations which could be used to simulate policy alternatives including deregulation programs. The authors found a price increase of 15 cents per Mcf applied to a 1973 price of 29.6 \$/Mcf and a $34 /$ Mcf additional increase per year thereafter would be enough to eliminate the shortage by 1979. The total estimated price increase was to $65.5 \$ /$ Mcf by 1980. Subsequent studies by MacAvoy and Pindyck (1975b) (a) have raised their estimate to a market-clearing price of $\$ 1.003 /$ Mcf in 1980 . Thus, the most recent of MacAvoy and Pindyck's published predictions of the market clearing price in 1980 dollars is below recent actual market prices. Given this performance, the value of the model in estimating price distortion is doubtful.

The Khazzoom and Erickson-Spann models provide widely divergent estimates of the price increases necessary, starting in 1974, to clear the market by 1980. The Khazzoom model would require the largest price increase, about 50 percent, since its estimates of quantity demanded are less price sensitive. The Erickson-Spann model would require only a 2 to 3 percent price increase to reach the same goal. Much of this difference can be attributed to uncertainty regarding the correct model specification, a problem common to econometric models (Pindyck 1974, p. 642). (b)

Other econometric models of the natural gas industry have been developed by Robert B. Helms (1974) and by Edward E. Ives and Milton L. Holloway (1977).

(a) An intermediate estimate can be found in MacAvoy and Pindyck 1975a, Table 2.4.

(b) The method of evaluation is camparison of root-mean-square error and mean error. The MacAvoy-Pindyck model performs best on two of the tests. 
While Helms does not explicitly estimate the price distortion, his model does provide an alternative economic model of the natural gas industry. Ives and Holloway in a 1977 study estimate that deregulating natural gas well head prices and eliminating "rolled in "pricing would result in a market price of $\$ 2.40 /$ Mcf in 1977 followed by $\$ 2.54 /$ Mcf, $\$ 2.20 /$ Mcf and $\$ 2.18 /$ Mcf in 1978 through 1980. By 1985, the price would drop to $\$ 1.83 /$ Mcf. This is not drastically different from the prevailing (1975) unregulated intrastate price. However, the low 1985 price is due to new supplies found in response to the $\$ 2.54$ price assumed for 1978 .

\section{Noneconometric Estimates}

The U.S. Federal Power Commission (1975) has reviewed most of the major econometric models as well as a variety of natural gas studies in an examination of the costs of deregulating the natural gas industry. Table 2 provides estimates of the deregulated price given in several studies reviewed by the FPC. The estimates appearing in Table 2 "are based on a variety of assumptions. The price estimates of these studies range from $\$ 0.75 /$ Mcf to $\$ 1.75 /$ Mcf for a "free market" wellhead price of natural gas.

In addition to summarizing and evaluating a variety of past studies, the Federal Power Commission has provided its own estimates of the deregulated wellhead price of gas. It is worth observing that in this study, as well as most of the others, the predicted deregulated price is sensitive to a variety of parameters whose values are not precisely known. The 1985 price could be between $\$ 1.486 /$ Mcf and $\$ 0.815 /$ Mcf. Further detail from this FPC study is given in Table 3 . 
TABLE 2. Selected Deregulation Studies Examined by the FPC

\begin{tabular}{|c|c|c|c|}
\hline Deregulation Study & $\begin{array}{c}\begin{array}{c}\text { Extent } \\
\text { of }\end{array} \\
\text { Deregulation }\end{array}$ & $\begin{array}{l}\text { Time } \\
\text { Period } \\
\text { Covered } \\
\text { by } \\
\text { Study }\end{array}$ & $\begin{array}{l}\text { Free Market } \\
\text { Price of } \\
\text { New Gas } \\
\text { at Wel lhead } \\
\text { Assumed in } \\
\text { Calculations } \\
\quad \$ / M c f \\
\end{array}$ \\
\hline Foster - API (a) & All Sales & $1974-80$ & $\$ 0.75$ \\
\hline Schwartz ${ }^{(b)}$ & New Gas & $1975-80$ & $\$ 0.75-\$ 1.25$ \\
\hline Project Independence ${ }^{(c)}$ & New Gas & $1974-85$ & $\$ 1.00$ \\
\hline $\begin{array}{l}\text { Kumins - Library of } \\
\text { Congress }(d)\end{array}$ & Total Deregulation & $1974-80$ & $\$ 1.75$ \\
\hline
\end{tabular}

(a) Foster Associates, Inc. August 1973. The Impact of Deregulation on Natural Gas Prices. Report for American Petroleum Institute. Washington, DC, Projections are also made for three other prices.

(b) Schwartz, Davis S. Letter of September 25, 1974, to Senator Warren G. Magnuson.

(c) Federal Energy Administration. November 1974. Project Independence Report. Superintendent of Documents, U.S. Government Printing Office, Washington, DC, 20402. Also makes projections on prices from 406 to $\$ 2.00 /$ Mcf.

(d) Kumins, Lawrence. November 1974. Economic Impact Report on Deregulation of Natural Gas. The Library of Congress, Congressional Research Service, Economics Division. (Prepared for the Honorable John E. Moss, Chairman, House Comittee on Commerce and Finance).

\section{TABLE 3. Federal Power Commission Marginal Supply} Price Predictions, 1985 (Ful1 Deregulation)

\begin{tabular}{lccccc} 
& \multicolumn{1}{c}{ Level Production } & & Level Additions \\
& $\underline{e=0.1^{(a)}}$ & $\underline{e}=0.2$ & & $\underline{e}=0.1$ & $\underline{e}=0.2$ \\
FRC Demand (b) & 1.486 & 1.149 & 1.181 & 0.982 \\
RES Demand & $(c)$ & 1.136 & 0.959 & 0.872 & 0.815
\end{tabular}

(a) $\mathrm{e}=$ supply elasticity; residential demand elasticity $=3 \mathrm{e}$. Elasticity is $\%$ change in quantity for a $1 \%$ change in price.

(b) Refers to the demand forecast from Future Requirements Committee. See FPC 1975, p. 25-27.

(c) Refers to demand forecast from Reference Energy System. See FPC, 1975, p. 25-27. 
Another estimate not based on a model has been made by Albin Dahl (1976, pp. 24-32). His methodology is similar to that of Kumins (1974) cited in Table 2; he compares Btu delivered per Mcf of natural gas with the price of $0 i 1$ on a Btu content basis. His estimate of the deregulated price is about $\$ 1.50$ Mcf.

An attractive aspect of noneconometric estimates is that they seem to provide ballpark estimates with minimal time and expense. However, the Dahl and Kumins studies suffer from the assumption that consumers base fuel and heating choices solely on cost per Btu without regard for the other attributes of the fuel. In addition, they disregard the effects of the higher unregulated price in stimulating gas production. This problem is also common to studies based on the price of unregulated gas in intrastate markets or substitutes such as synthetic gas from coal or imported liquefied natural gas. As mentioned earlier, these prices reflect what a customer deprived of regulated gas is willing to pay; this amount is high because price controls and regulation have caused a shortage. The unregulated price would undoubtedly be lower.

Monopoly

The initial stated purpose of natural gas regulation was to protect consumers from the higher prices of possible monopoly. If the fear of monopoly pricing was well founded, eliminating the regulatory framework will not produce a distortion-less price. In that case, the regulated price would probably be closer to the social cost of producing natural gas than any alternative involving deregulation.

The usual method of evaluating the quality of competition in a particular market is to examine the structure and behavior of the industry. While the present structure and behavior of gas producers may be shaped by regulation, the gas industry does not appear to be less competitive than most of U.S. manufacturing. Analyses of market structure indicate there were 3745 producers in 1971 selling natural gas in interstate commerce with sales of the largest producer capturing around 9.2 percent of total interstate sales. The industry concentration ratios are below average for U.S. manufacturing (Helms 1974, p. 9; Lee 1974 , p. 18). When considered on a regional basis, however, many 
companies have monopoly power. Information on performance is likely to be so seriously affected by regulation as to be worthless as an indicator of the likelihood of reaching a competitive price in the absence of regulation.

While economists hold opposing views on the strength of competition in the natural gas market, little actual evidence has been found of monopoly. Paul MacAvoy (1970, p. 168) concludes "... gas markets are diverse in structure and behavior, but are generally competitive or changing from monopoly toward competition." If deregulated, U.S. antitrust laws would apply to natural gas firms, and any monopolistic price distortions would be held within limits. Given the existence of regulation, monopoly in the gas industry does not cause price distortions that can be estimated.

\section{Taxation and Subsidies}

The past few years have seen large changes in national taxation policy relating to energy sources. The 1976 removal of the mineral depletion allowance for larger natural gas and petroleum producers has probably eliminated the major distortion due to taxation and subsidies.

None of the studies analyzed the effect of any special government taxation program on the final consumer price of natural gas. A study by Pacific Northwest Laboratory for the Department of Energy, itemizing the major incentives and tax advantages provided to various energy sources, found the total incentive to the natural gas industry to be over 15 billion dollars (Cone et al. 1978, p. 251). No attempt was made to evaluate effects of this subsidy on the price of natural gas. Gerard M. Brannon (1974, p. 28) has extensively studied fuel and energy taxation. His estimate, completed before elimination of the mineral depletion allowance, was that natural gas companies faced a much lower effective tax rate than other corporations. He calculated an effective tax rate for gas that is 70 percent less than that for all corporations or an effective rate of only 10 to 15 percent.

\section{Health and Environmental Effects}

Combustion of natural gas releases less of most types of air pollutants than combustion of any other fossil fuel. Release of sulfur dioxide is particularly reduced. In addition, the occupational accident rate is lower 
than that for the other fossil or nuclear fuels (U.S. AEC 1974). None of the sources reviewed treated the health and environmental effects of natural gas other than superficially. The damaging effects of gas leaks, explosions and fires were not even mentioned.

Conclusion

The largest net price distortion in natural gas markets appears to be caused by government controls on wellhead prices. Since the "free market" price is unobservable, we must use proxies or estimates to actually measure the size of the distortion. Estimates from already existing econometric models such as MacAvoy-Pindyck or Ives-Holloway are consistent with economic theory, but cannot project change involving significant price increases. Recent price increases authorized by the FPC, as well as attempts to deregulate the industry lead to the suspicion that the magnitude of past estimates of price distortion overstate the current situation. Information on the probable effects of the Natural Gas Policy Act was not available at the time of this analysis.

\section{ELECTRICITY}

Estimating the magnitude of price distortions is a more difficult task for electricity than for other fuels. Production of electricity from coal, nuclear, 0i1, gas and hydro results in a changing mix of fuel sources and hence external costs. The federal government has been active in the provision and marketing of electricity and has regulated interstate sales through the Federal Power Commission. Utility prices to final consumers are set by a regulatory commision and a municipal body may even own and operate the utility. Since there are rate schedules for different customers, distortions can occur in some rates and not others. These tiers of regulations and government involvement add to the difficulty in analyzing and estimating the social cost of producing and distributing electricity.

In addition, the ability of utilities to produce electricity from a number of fuels results in some uncertainty about the effect of one fuel price change on the final price of electricity. As a fuel's price changes relative to the price of other fuels, the utility will substitute away from the 
more expensive fuel. Since the utility will reduce the amount of the more expensive fuel, correcting a distortion in one fuel price will not result in a simple "pass through" effect on the price of electricity. There are also differences in price effects because various areas of the country use different fuel mixes. For instance, the Pacific states produce two-thirds of their electricity using hydro and only 1.7 percent with coal. A change in the price of coal will have much less affect on the price of electricity in the Pacific states than in an area like the East Central states which use about 80 percent coa1 (FEA 1976, p. 241).

These difficulties have led to fewer estimates and less confidence in existing estimates of the social cost of electricity than for other energy sources. Much more study and research would be necessary before an adequate estimate of the external costs could be developed.

Monopoly

Public utility regulation has been instituted due to tendencies toward natural monopoly. Whether existing utility regulation has reduced the resulting price distortion or not is discussed in the section on regulation. Here the concern is with monopolization of the input fuels used to produce electricity, in particular coal and uranium. $0 i 1$ and gas were analyzed in separate sections; little evidence of monopoly distortions was found. Hydro is produced and marketed under Federal regulatory constraints.

In general, a monopoly price is more likely in an industry with few producers and expensive entry requirements for new firms. In the following discussion, four-firm concentration ratios are used to indicate the likelihood that the industry's structure tends to promote monopoly. Evidence of monopoly pricing is inferred from large and otherwise unexplainable profits or behavior incompatible with competition.

\section{$\underline{\text { Coal }}$}

While the four-firm concentration ratios for coal are not large, they have increased from 16.5 percent in 1955 to over 30 percent today (Duchesneau 1975, p. 76). There are several reasons for this increased concentration, including the introduction of the unit train, the increased use of long-term contracts 
and increases in large generating plant economies (p. 179). In spite of the increase in plant size, studies indicate entry barriers do not appear to be formidable ( $p$. 178).

Because the major coal companies are controlled by non-coal firms, profit data on coal operators are difficult to obtain. The coal production information is submerged in the general information on operations of the parent firm. The rates of return for small individual producers have begun to reflect improved prospects for the industry, but do not appear to be larger than those of manufacturing firms (Duchesneau 1975, pp. 158-159).

A major study of competition in the energy field by Thomas D. Duchesneau (1975) analyzed the charges of monopolization and the effects of oil and other non-coal companies expanding into coal. The study concludes that "workable competition in domestic coal production appears to be the case." In addition, future prospects for competition seem to be enhanced by the preference for lowsulfur coal, which tends to be controlled by different firms than those producing high-sulfur coal.

\section{Uranium}

Uranium is the most rapidly growing fuel source for electricity. By 1985 it is expected to provide 26.1 percent of the electricity produced, compared to 6.0 percent in 1974 (FEA 1976, p. 238).

Levels of concentration in the uranium mining and milling industry have been relatively high. The largest firm produces over 20 percent of the tota1. The four-firm concentration ratio in 1971 was 54.4 percent, and the eight-firm ratio was 78.5 percent (Duchesneau 1975, p. 88 ). These ratios are relatively high for U.S. manufacturing.

The Atomic Energy Commission (now Nuclear Regulatory Commission) has acted to prevent the price of uranium from falling to competitive levels. It has barred imports of $\mathrm{U}_{3} \mathrm{O}_{8}$ and stockpiled uranium; both policies have led to stable prices in the presence of excess capacity (Duchesneau 1975, p. 180).

Thomas Duchesneau's Ford Foundation report (1975, p. 180) on competition in energy industries concluded that the market for uranium is more monopoly prone than other fuel markets. Concentration levels are high enough in the 
case of uranium mining and milling to raise serious doubts as to the effectiveness of competition. Duchesneau does not provide any quantitative evidence of the magnitude of possible monopoly pricing, nor is his evidence of high concentration sufficient to conclude that monopoly or collusive pricing exists. However, of all fuel sources, uranium has the greatest possibility of monopoly price distortions.

Taxation and Subsidies

This section examines the few studies available and briefly describes the extent of government subsidies and incentives for the major fuel sources. None of the studies attempted to estimate the final effect on electricity prices of all government programs. These programs affect both electricity production costs and distribution costs through subsidies such as the guaranteed loan programs of the Rural Electrification Administration.

\section{Coal}

The U.S. Government has subsidized research, development and exploration for all fuel sources. For coal, estimates place research and development expenditures by the government at $\$ 394.8$ million, and at $\$ 3.5$ million for data collection and analysis by the Bureau of Mines. In addition, an indirect subsidy of about $\$ 75$ million per year to the coal industry is provided through expenditures on ports and waterways (Cone et a1. 1978, pp. 172, 189, 197).

Taxation of coal revenues has been subject to a depletion allowance similar to allowances for $0 i 1$ and gas. The current percentage allowance is 10 percent of the value of production at the mine mouth. The maximum allowance is 50 percent of the income from the property (Cone et a1. 1978, p. 185). After all conditions are considered, the effective depletion rate is around $6 \%$. This generated an estimated $\$ 392$ million tax advantage in 1976 or about $\$ 0.57$ per million Btu (Brannon 1974, p. 12).

\section{$\underline{\text { Uranium }}$}

The Federal Government has also subsidized the development and support of the domestic uranium industry. Many of the price effects are difficult to quantify. For instance, the Price-Anderson Act, which limits the liability of the nuclear industry, had a significant but currently unquantified effect on the commercial price of nuclear power. 
The subsidies provided by the Federal Government come from a variety of programs including waste management, nuclear materials research and development, safety research and facilities plus a host of supporting contributions. One estimate of the total federal subsidy to the commercial nuclear industry in 1976 has been placed at $\$ 929$ million (Cone et al. 1978, p. 120).

In addition to the research and development programs, the government has provided certain uranium enrichment services at prices significantly below costs. An estimate of this subsidy is about $\$ 22.65$ per separative work unit or a total subsidy through 1974 of about $\$ 500$ million (Cone et al. 1978, pp. 141-142). No estimate of the effect of this service on the price of electricity has been made, but since the price of uranium is a small electricity cost component, the effect is not likely to be large.

\section{Hydro}

The government has constructed and operates dams and hydro facilities. It is currently marketing electricity through the Tennessee Valley Authority, the Bureau of Reclamation, the Bonneville Power Administration, Southwestern Power Administration, Southeastern Power Administration and the Alaska Power Administration (Cone et a1. 1978, p. 155). These programs have undoubtedly lowered the price of electricity but no estimates were found of the amounts in each region. A national estimate places the total of these subsidies plus the effective subsidy of an income tax exemption on private utilities who purchased portions of their power from federal programs at $\$ 9.2$ to $\$ 17.4$ billion through 1976 (p. 170).

Regulation

This section considers pricing distortions caused by regulation of the. production and sale of electricity. The effects of the many environmental and health and safety regulations are not assessed here since they are designed to reduce previously existing distortions. However, it is recognized that these regulations could increase the price of the product beyond the social costs of production. The effects of the Interstate Commerce Commission's regulation of railroad tariffs for the transportation of coal and distortions from rate regulation of investor-owned utilities were investigated. Investorowned utilities provide 78 percent of the kilowatt sales in the United States (FEA 1976, p. 246). 


\section{Public Utility Regulation}

The regulation of public utilities is considered desirable because economies of size in the production of electricity enable one firm to supply the market at lower cost than two or more firms. However, if the producing firm is not regulated, it will charge the monopoly price. Hence, in return for restrictions on the entry of possible competitors, utilities have their rates set by a utility commission.

Generally, the "best" price to set for a product is the price that equals marginal cost. However, for electricity with declining average costs, marginal cost lies below average cost. To set a price equal to the marginal cost would result in continuous losses for the regulated firm and it would stop producing. Thus, the distortionless price cannot be charged without subsidies to the utility. As a result, average cost pricing is the goal of most regulatory bodies.

At least two studies have attempted to determine if the price of electricity under rate regulation differs from the likely unregulated price of electricity. Stigler and Friedland (1972, pp. 1-16) found that regulation had no effect on electricity prices and concluded that regulators were assuming an impossible task in attempting to set and enforce rates, outputs and costs. The lack of difference between unregulated and regulated prices may be due to residual effects of monopoly on regulated prices or conversely may indicate that monopolistic pricing is not a problem and that regulation is neither effective nor necessary. On the other hand, the models used to project unregulated prices may be at fault. We know of no solid evidence to aid in evaluating the merits of the possible explanations. An econometric study by Moore (1975) concluded that electricity prices increase with the level of regulatory activity. However, Moore's study and conclusion has been extensively criticized by Marchand and Sorensen (1977).

The rate structure as well as the overall rate level may create price distortions. Under the present pricing structure of most utilities, the same price is charged for electricity regardless of whether it is produced in peak or off-peak periods. During peak use periods, with the system approaching capacity, customers purchasing electricity are imposing the full 
costs of system capacity. The capacity is built to accommodate such peakload service. Customers at off-peak times are imposing lower costs on society, essentially because of lower rates of capital usage and deterioration. Peak period electricity and off-peak electricity may be considered as two different products. If they are priced at social costs, peak-load prices will be substantially greater than off-peak prices. Thus, price distortion is created by a regulatory system that prices all electricity at the same rate. There have been estimates of the gain from changing to a structure that prices peak-load electricity at a higher rate (Sharefkin 1974). Since this is a change in the structure rather than a single correction of a distorted price, the studies do not provide information that can be expressed as an estimate of price distortion.

\section{Transportation of Coal}

Many economists believe the Interstate Commerce Commission (ICC) has acted to set transportation rates above the marginal costs of providing the service. In addition to higher rates, the ICC has acted in ways that increase the costs to society of transporting products. (a) Coal is the fuel most affected by ICC policies since over one half of it is shipped to electric utilities by rail (Coal Traffic Annual 1973, p. 46).

There have been several estimates of the railroad rate reduction under deregulation. Thomas Moore (1975, pp. 66-67) estimates an average reduction of $20 \%$ for all railroad rates. The reduction for coal may be very different than the average since rates allowed on finished goods are usually higher than rates on raw materials (Moore 1972, p. 51). Ann Friedlaender (1969, p. 73) estimates the percentage deviation of actual from optimal prices to be lower for mine products than for other categories. Her estimate is that prices are about 6 percent higher than optimum. Other studies suggest that the ratio of revenue to out-of-pocket costs for coal is relatively low (Moore 1972, pp. 8485). Unless the ratios for coal are less reliable than for other commodities, the price distortion appears much lower for coal than for most other products.

(a) See Friedlander 1969 and 1971; Moore 1972 and 1975. 
If regulation of rail transportation of coal results in transportation charges which are only $6 \%$ to $10 \%$ above costs, its effect on electricity prices is small. Since one half of the coal used is transported by rail under ICC regulations and, according to a 1969 estimate by Friedlaender (1969, p. 150), 42 percent of the delivered wholesale price of coal is due to freight costs, the effect on the price of electricity from deregulating coal freight rates would be close to zero.

Health Effects

There are health effects associated with each stage in the production and delivery of electricity; impacts result from mining, transporting and converting fuels into electricity and transmission of electricity. While none of the studies reviewed mentioned the number of people who are burned or electrocuted annually, a social cost exists nonetheless. External costs resulting from use of coal, nuclear and hydro in production of electricity are discussed below. The comparable costs associated with the use of oil and gas in electricity generation were covered in the previous sections.

$\underline{\text { Coal }}$

Coal production has an abysmal record of negative health impacts. The occupational injury rate alone is a minimum of five times higher for coal than for alternative fuel cycles as illustrated by Figure 4. In transporting coal, which is done mainly by train, additional numbers of people are maimed or killed every year. Sagan (1974, pp. 107-111) estimated that 230 people are killed and 2,000 injured annually by trains transporting coal to power plants. These health impacts, in addition to those from emissions, add up to substantial external costs from use of coal. The health cost of sulfur dioxide emissions alone before 1975 was estimated to be from $\$ 7$ to $\$ 38$ million dollars a year per 1000 MW plant depending on the population density downwind (North and Merkhofer 1975).

Hydro

None of the studies reviewed dealt with the health impacts of hydro power. The main source of damages is the failure of a dam with resultant injuries and 
loss of lives. The lack of information in the literature may be due in part to the difficulty of constructing damage functions for such low-risk, highcost events.

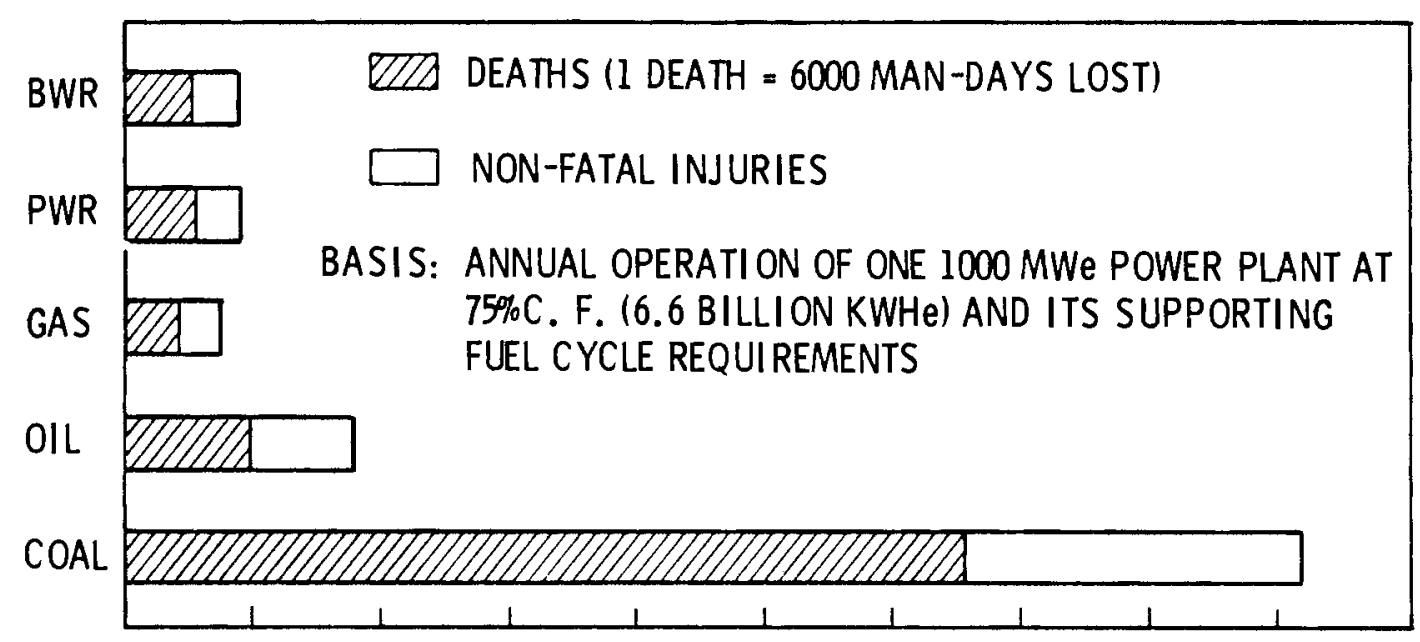

MAN-DAYS LOST DUE TO OCCUPATI ONAL ACCIDENTS

FIGURE 4. Annual Occupational Injuries in the Alternative Energy Systems

Source: U.S. Atomic Energy Commission 1974.

\section{Nuclear}

The health costs associated with the nuclear fuel cycle include the effects of occupational and transportation accidents and radiation exposure of miners, plant employees and the general population. Information on accident rates is readily available, as are a range of risk and damage estimates for the population as a whole. Some, if not most, of these health costs are covered by insurance and workman's compensation contributions of the nuclear industry and thus are internalized costs. Health costs paid for through the mechanism of the Price Anderson Act on the other hand would constitute external costs. In spite of the lack of documentable evidence of external health costs related to nuclear energy, the activities of anti-nuclear groups indicate that they 
perceive uncompensated costs. The stress of living with risk levels perceived as undesirable creates a mental health cost which is no less real because it is unquantified. However, there is no indication of whether this cost is greater or less than unquantified costs associated with other fuel cycles.

Environmental Effects

Environmental effects may take the form of physical changes in water, air or other resource quality or of perceived changes in the visual quality of a landscape. For example, residents of the region surrounding a power plant may be as affected by the sight of immense natural draft cooling towers as they are by the emissions from them. Electricity production regardless of the source fuel affects the scenery in ways that are generaliy considered to be negative. This is due to the existence of smokestacks or cooling towers, plumes and transmission lines. Estimates of the value of damages were not included in the studies reviewed though such estimates could be made. The value of the aesthetic impacts of transmission lines could be approximated through estimates of what people are willing to pay to have the lines buried or located elsewhere. Research is currently under way at Pacific Northwest Laboratory to develop estimates of the aesthetic impacts of cooling towers.

\section{Coal}

Deep mining and strip mining of coal produce two different sets of environmental costs. Regulation of both types of mines has been increasing, however, and there is evidence that external costs have decreased significantly since 1960. (Howard 1977, pp. 76-101). In the case of deep mining, the major impacts result from land subsidence over mined areas and acid mine drainage. For 1970 the costs of subsidence were estimated by Dials and Moore (1974) to amount to $\$ .50$ per ton mined and costs for acid mine drainage were $\$ .06$ to $\$ .20$ per ton mined. A recent study by Randa11 (1978) examined the aesthetic, water quality, flooding, wildlife and recreation impacts of surface mining. The net present value of social costs was estimated to be between $\$ .40$ and $\$ 9.14$ per metric ton depending on the number of people considered to be affected. 
Hydro

Hydro-generated power affects the environment through normal operation and particularly in the event of dam failure. Normal operation interferes with the life cycles of indigenous organisms such as the salmon in the Pacific Northwest. At the same time there are benefits in the form of recreational opportunities and flood control. The most serious environmental costs may be those which occur in the event of dam failure; estimates of such damages have become available in recent years. However, constructing regional risk estimates and damage functions would be a difficult task. Since dams are generally multi-purpose, separating the environmental costs and benefits attributable to electricity generation is nearly impossible.

\section{Nuclear}

The major noncatastrophic environmental impacts of the nuclear fuel cycle result from uranium mining. Whether deep mining or open pit methods are used, the extraction of uranium from the ore leaves most of the ore volume in the form of mill tailings. Estimates of the resulting environmental damages were not found in the literature surveyed and most of the concern about mill tailings centers on the release of radioactive particles in the air and water with resultant health risks rather than on disruption of the environment.

\section{CONCLUSIONS FROM EMPIRICAL ESTIMATES}

There is evidence that the damages resulting from fuel production and conversion have been reduced considerably in recent years. Much of the cost of damage prevention is being borne by fuel producers but some of the rest of the cost is still being assumed by the public sector. As a result a portion of the total cost of fuel production is being borne by the whole country rather than just by miners, the population near a power plant or the users of a particular fuel. While equity concerns dictate that the users of a fuel should bear the net costs, that is not the present case and may be impossible to carry out in practice. 
Significant gaps between the market price of a fuel and the cost of producing and using it remain in some areas in spite of recent improvements. For natural gas the main source of price distortion is the regulatory structure that controls prices. The price of oil, on the other hand, does not appear to differ greatly from its social cost to the U.S. The degree of distortion in electricity prices varies between regions depending on energy sources used and the prices charged. Much of the existing electricity price distortion is due to either the level of government subsidization of the costs of nuclear power or the environmental costs of coal. The variance in estimates of social cost is generally greater in magnitude than the average of the social cost estimates. Thus the costs of estimating social costs may not be justified by the quality of the estimates which can be generated currently. 


\section{LIFE CYCLE COST MINIMIZATION}

The Energy Conservation Standards for New Buildings Act of 1976 stipulates that building energy conservation standards be analyzed in terms of their benefits and costs. Ideally a standard should maximize net social benefits; to accomplish this, a building energy performance standard must lead to a minimization of energy-related life cycle costs without decreasing the value of building services. The use of energy-related life cycle cost minimization as a design criterion is appropriate whether the standards developed are prescriptive, component performance or building performance standards.

The role of the life cycle cost model in determining an appropriate design energy budget is shown in Figure 5 . The model integrates the social cost of the capital and fuel resources used with the physical quantities of fuel required to satisfy space conditioning and lighting requirements. The social cost of each fuel consists of both the private cost or market price of the

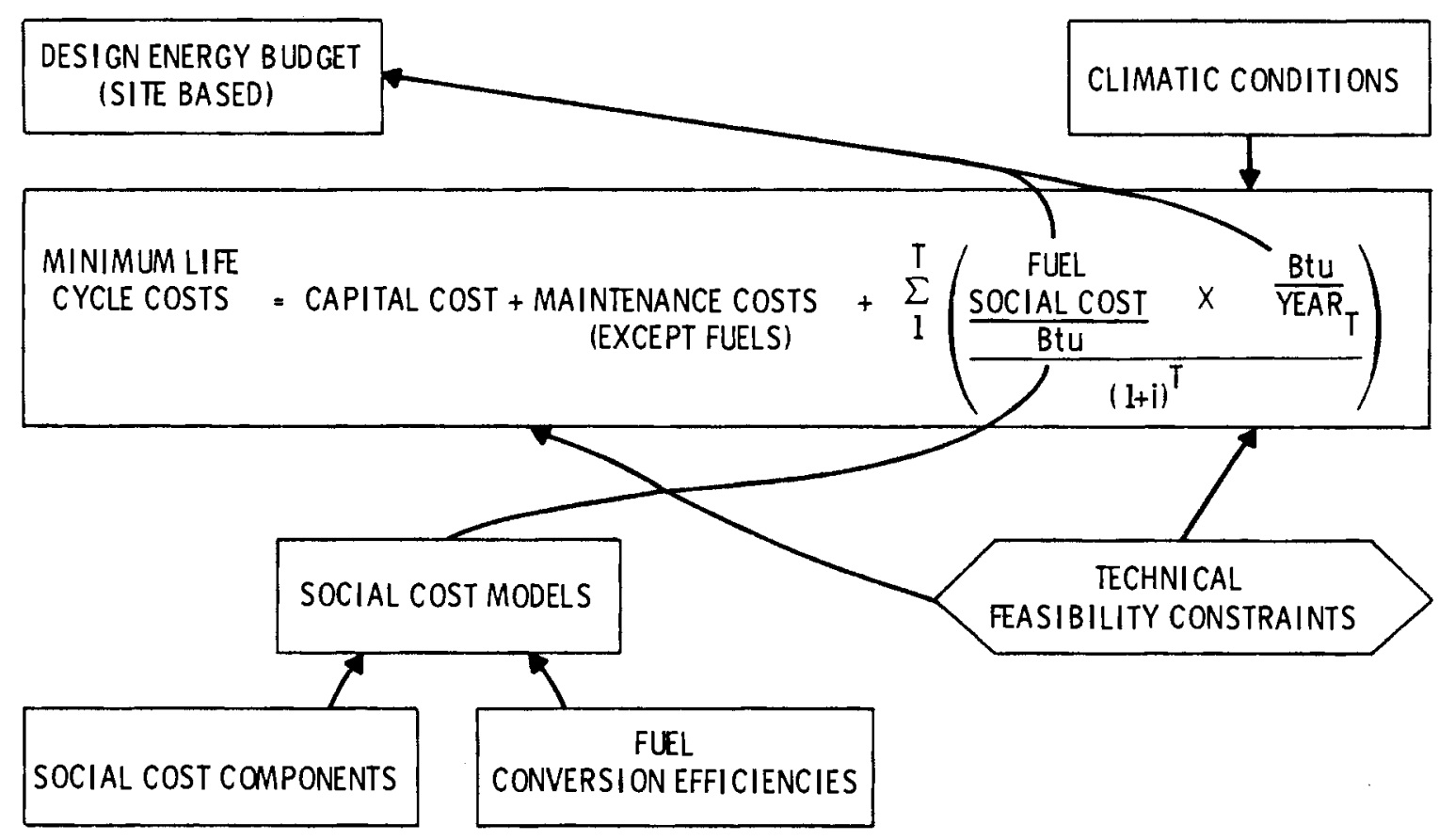

FIGURE 5. Design Energy Budget Derivation from the Life Cycle Model 
fuel and the nonmarket or external costs associated with use of that fuel. In this model the design energy budget is determined by the rate of tradeoff of fuel cost for capital and maintenance costs.

The use of a life cycle cost framework to compare capital and energy consumption tradeoffs involves the determination of values for several key parameters. First, an appropriate discount rate must be determined in order to calculate the present worth of future expenditures. Second, an appropriate discount period must be determined. And third, the value to society of both capital and fuel inputs must be known and the change in relative costs of substitutable fuels during the discount period must be estimated. Methods for determining these parameters are described in the following paragraphs. These descriptions are followed by a discussion of the uses of a life cycle cost model.

\section{LIFE CYCLE COST MODEL FORMULATION}

A life cycle cost model used to develop energy performance standards should include all the relevant costs such as initial component costs, maintenance costs, and fuel costs expressed on a consistent discounted basis. Initial component costs include the price of the component plus the net present value of expected service and operating costs over the discount period. Fuel costs should be estimated by taking the net present value of costs based on fuel price escalation projections. In addition to these costs, the salvage value of the capital equipment, if any, must be considered as a residual at the end of the discount period. The major elements of a life cycle cost model are illustrated in Figure 6 .

\section{CRITICAL PARAMETERS}

The capital and fuel utilization decisions resulting from use of life cycle cost models for building energy performance are sensitive to the parameters used in the calculation of net present value. These include the discount rate, the discount period and the relative escalation rates of various fuel prices. 
MINIMIZE

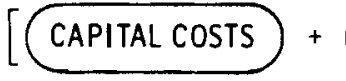

MAINTENANCE COSTS

FUEL COSTS

SALVAGE VALLE

WHERE :

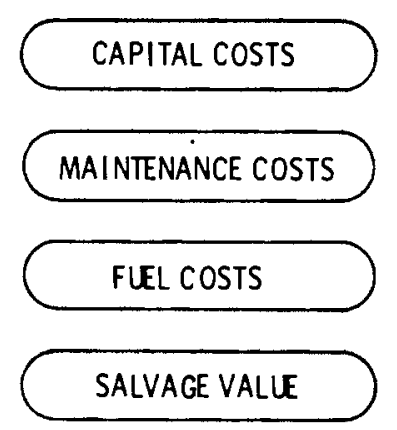

INCLUDE COSTS OF INSULATI ON, WINDOWS, HEATING + COOLING SYSTEMS, ETC. AND THE NET PRESENT VALLE OF RELATED INTEREST EXPENSE

ARE THE NET PRESENT VALLE OF EXPECTED ANNUAL ENERGY SYSTEM OPERATION AND MAINTENANCE COSTS

ARE THE NET PRESENT VALUE OF EXPECTED AIUN'NUAL BTU CONSUMPTION

IS THE PRESENT VALUE OF THE CAPITAL EQUI PMENT AT THE END OF ITS LIFE CYCLE

FIGURE 6. Life Cycle cost Model

Discount Rates

The selection of an appropriate discount rate involves determining the rate at which people are willing and able to trade current income for future gains. Indications of this rate may be found in private capital markets such as the mortgage market. However, imperfections in capital markets (e.g., inability of all households to invest and borrow at the same interest rate, imperfect information, the effects of taxes and transaction costs) generate a complex interest rate structure within which rates vary based on risk and other factors. In making investment decisions that involve annual cash inflows or outflows, the discount rate used is usually the interest rate at which the individual or firm is able to borrow or the rate of return at which they can invest funds. These rates generally vary inversely with wealth.

When investments are considered from the perspective of society as a whole, a social discount rate is used. If our economy were free of market imperfections and income derived from capital investment were untaxed, then the social discount rate would equal the riskless market rate of interest as determined by the demand and supply of long term capital. Of course, markets are imperfect and the yields from capital investments are taxed. Given this situation, there is no obviously correct discount rate to be used to find the 
present value of a future stream of benefits and costs. The discount rate for society as a whole, however, is generally considered to be lower than that for individuals.

Whatever the discount rate chosen, care must be taken to treat inflation consistently throughout the calculation of net present value. Many people make the mistake of mixing current or constant dollars and market interest rates. Since market interest rates reflect the expected rate of inflation, they must be used in conjunction with dollars inflated for each year of the discount period. Only the "real" (inflation adjusted) discount rate should be used in conjunction with constant dollars. The use of any positive real rate of discount that is less than the market rate of interest will be likely to increase indications for energy conservation over current practice. Within a life cycle cost minimization framework as the discount rate is decreased, the optimal level of capital investment increases.

\section{Discount Period}

The appropriate discount period for minimizing life cycle costs from an individual's point of view is the expected length of building ownership. Actual average duration of ownership varies with the type of building, presently ranging from about 6 years for apartments and residences to much longer periods for factories and corporate headquarters.

From society's point of view, the appropriate discount period is the expected life span of the building. Basing the discount period on the expected useful life of a building creates a decision framework in which the capital investment is fully depreciated and all future operating costs are considered.

If the discount period used in minimizing life cycle costs is less than the life span of the building, the effect is to neglect the value of fuel savings in the future that would be associated with greater capital investment in the present. The use of a discount period that covers the expected useful life of the building, rather than the period of expected ownership, will lead to explicit inclusion of future energy costs in the building system investment decision. 


\section{Fuel Prices}

The expected changes in fuel prices over the discount period affect both the optimal level of capital investment and the relative merits of substitute fuels. The net present value of fuel costs will be more heavily influenced by current than by future costs. Thus, a high price escalation rate in the future may not keep a currently low priced fuel from being the one with lowest life cycle costs.

\section{USE OF LIFE CYCLE COSTING}

It is likely that individuals implicitly minimize life cycle costs when choosing a building energy system. However, two essential factors lead to differences between the decisions actually made and the results of modeling efforts undertaken to determine optimal levels of energy conserving capital investment. First, the individual discount period is shorter than the social discount period. Given that the average family moves every four or five years, the discount period used by the individuals is probably four to five years. Second, information and transaction costs are not included in the life cycle cost equation. The cost to individuals of examining the technically feasible energy conserving options and determining their relative merit may be far greater than the value of any possible fuel savings. Even if the information is available, the transaction cost (that is, the cost of obtaining the materials and the services of a contractor with the expertise and willingness to install them) may result in a life cycle cost minimization that is not energy conserving.

The salvage or resale value of the building, which affects life cycle costs, is also subject to an information problem. When an individual is seeking to determine the optimal amount of an energy conserving component, say insulation, he needs to consider the salvage value of that insulation. That is, he needs to consider the amount by which the insulation raises the market value of his building. The contribution to resale value of insulation may be lower than the value that the building insulation would have if its exact quantity were known; in other words, a prospective buyer may have difficulty determining the amount of insulation in an existing structure. An individual who is considering how much insulation to put in a new building or 
how much to add to an existing building has an incentive to put in less insulation as the expected salvage or resale value decreases. The easier it is for a prospective building buyer to determine the amount or type of energy conserving component, the less divergence there will be between life cycle cost models and actual investment. If information about the energy performance of a building were available at low cost, then the market price of the building would reflect the future energy costs of that building. Then the potential salvage or resale value would influence the building owner to minimize life cycle costs considering the full expected life of the building rather than his expected period of ownership. 


\section{EVALUATION OF RESOURCE UTILIZATION}

The evaluation of resource utilization for building conditioning and lighting has both economic and energy quantity aspects. These aspects may be handled in several ways. In the following sections the alternative approaches of RIF's and RUF's or social cost are discussed.

\section{RESOURCE UTILIZATION COSTS}

Life cycle cost minimization will indicate the optimal tradeoffs of various resources if their relative prices are "right". That is, the price of each resource must reflect its relative scarcity and all of the costs of producing and delivering that resource in a useable form. If all prices under- or overstate costs in the same direction and to the same degree there is no problem. It is when resource prices are distorted to varying degrees and in different directions that resource misallocation occurs.

The social cost of any resource is composed of the market costs of producing that resource, costs of avoiding damage resulting from the production and consumption process and the value of uncompensated damages. Figure 7 illustrates the fact that while production costs are usually borne by the firm, damage costs may be internalized by firms to varying degrees. Figure 8 shows the occurrence of internal and external cost in the production process without regard to who bears the costs. The greater the degree to which the producer of a resource bears the cost of avoiding damages (reclaiming strip-mined land, etc.) the closer the market price will be to the social cost. During the 1960s evidence came to light that the relationship between the internalized costs of production and the total social costs for some fuels resembled example $B$ in Figure 9. It became obvious that given such underpricing, energy resources were being wasted. Since that time, legislation affecting air and water quality, mine safety, price regulation and depletion allowances in taxation has been enacted. For the most part this legislation has served to make fuel prices more representative of the situation shown in example $A$ of Figure 9. Hence, the assumption basic to energy accounting that prices do not indicate relative social costs and values is only partially true of the current situation. 


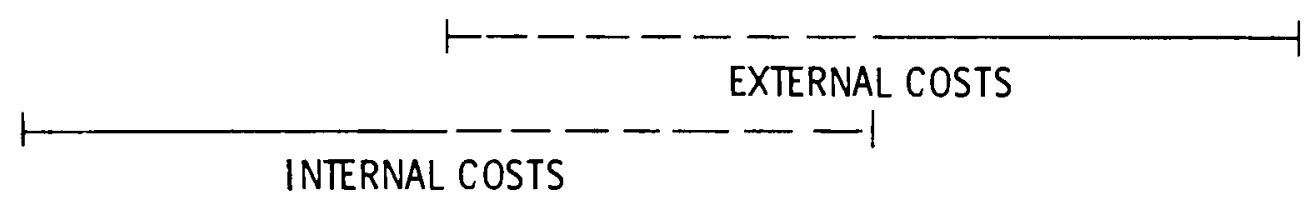

\begin{tabular}{|c|c|c|}
\hline $\begin{array}{c}\text { PRODUCTION COSTS } \\
\text { OF FIRMS }\end{array}$ & $\begin{array}{c}\text { DAMAGE ABATEMENT, } \\
\text { AVOIDANCE OR } \\
\text { MITIGATION COSTS }\end{array}$ & RESIDUAL DAMAGES \\
\hline
\end{tabular}

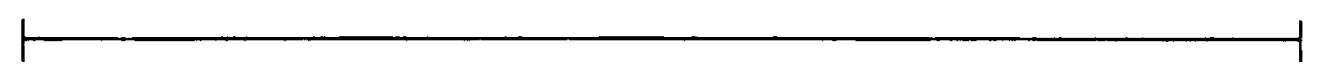

TOTAL SOCIAL COST

FIGURE 7. Components of Social Cost

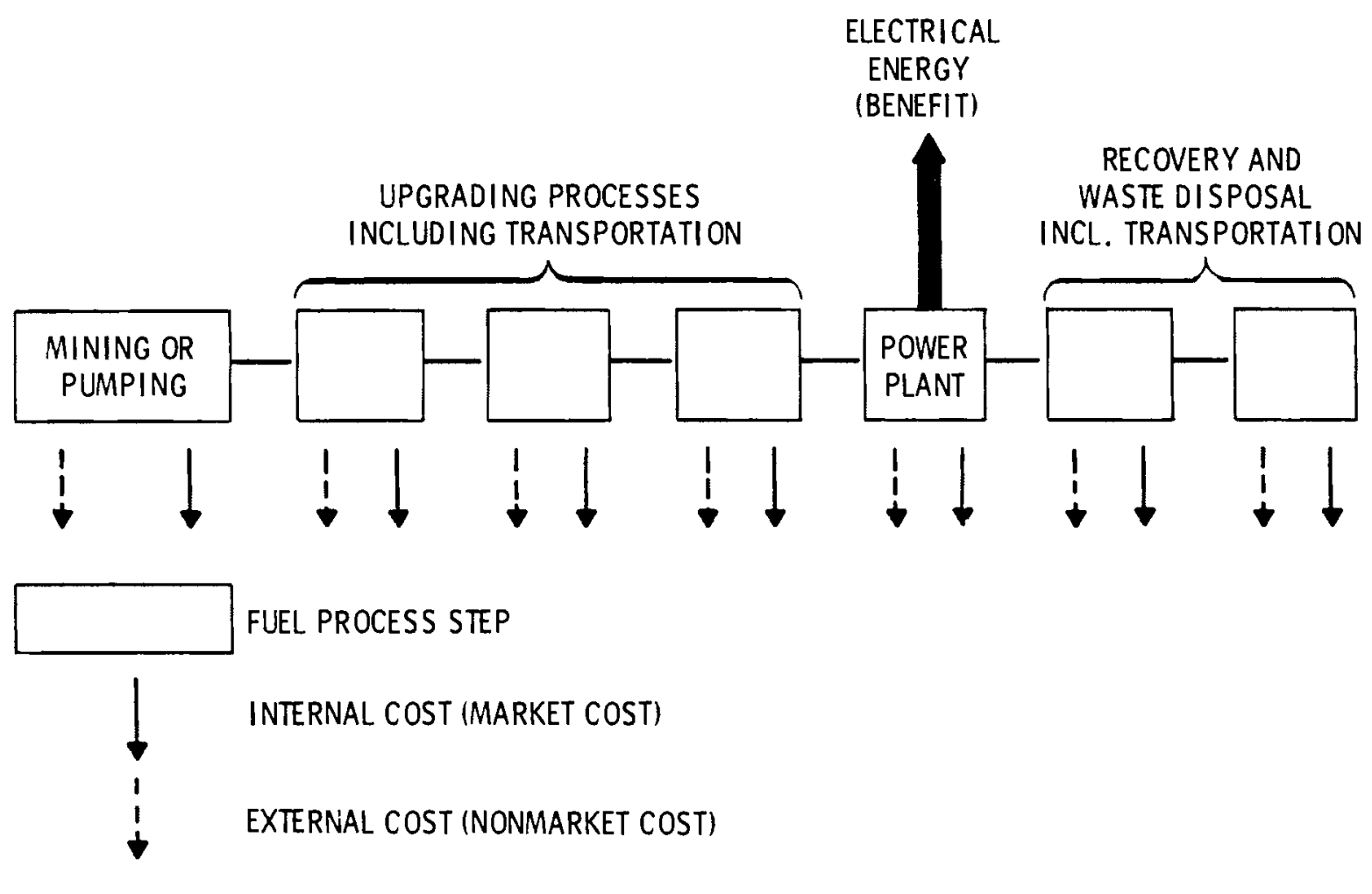

FIGURE 8. Schematic of a Fuel Cycle (Energy Production System) 


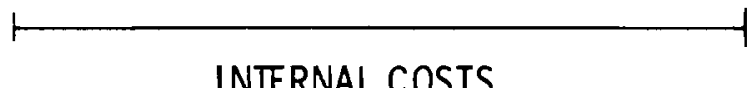

INTERNAL COSTS

A

\begin{tabular}{|c|cc|}
\hline $\begin{array}{c}\text { PRODUCTION COSTS } \\
\text { OF FIRMS }\end{array}$ & $\begin{array}{c}\text { DAMAGE ABATEMENT } \\
\text { COSTS }\end{array}$ & RESIDUAL DAMAGES \\
\hline
\end{tabular}

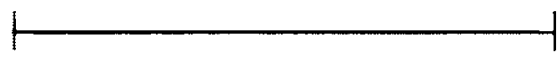

INTERNAL COSTS

B

\begin{tabular}{|c|cc|}
\hline $\begin{array}{c}\text { PRODUCTION COSTS } \\
\text { OF FIRMS }\end{array}$ & $\begin{array}{c}\text { DAMAGE ABATEMENT } \\
\text { COSTS }\end{array}$ & RESIDUAL DAMAGES \\
\hline
\end{tabular}

TOTAL SOCIAL COST

FIGURE 9. Relative Internalization of Damage Costs by Producers

\section{SOURCE ENERGY ACCOUNTING (ENERGY ANALYSIS)}

To deliver energy in a form suitable for a given end use (e.g., space heating or lighting), a number of processing steps, each entailing some input energy and some losses of the energy being processed, are required. These energy inputs and losses for any process may range from being very sma 11, as in the transmission of natural gas, to being very large, as in the enrichment of uranium or the conversion of fuels to electricity. Figure 10 illustrates a possible fuel refinement trajectory composed of processes that transform the energy from the natural resource to an end use at some location. Source energy accounting (commoniy referred to as energy accounting) traces the energy losses and inputs for a given trajectory to identify the total energy required to satisfy a given end use.

There have been two major reasons for the development of source energy accounting. The first is that 011 and gas are gradualiy being replaced by other energy forms (e.g., coal, nuclear and solar), which require relatively greater source energy because of the greater processing necessary to gather, convert and deliver energy in a form suitable for a given end use. Source energy accounting can identify the total energy resource use of alternative 


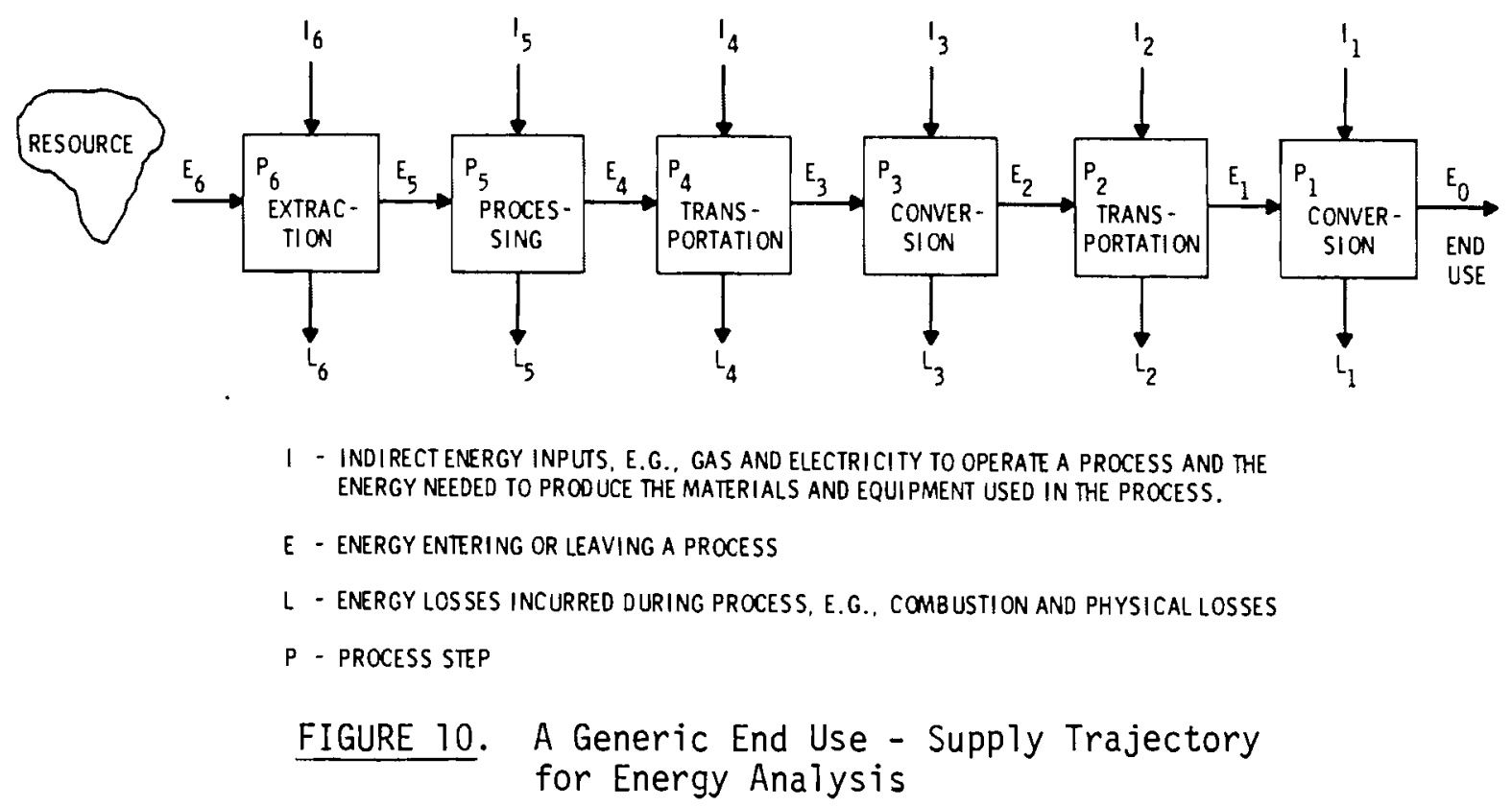

supply trajectories for a given end use. The second motivation is based on the assumption that, for reasons discussed elsewhere in this paper (e.g., industry structure and government regulation), energy prices are so distorted that relative prices do not adequately reflect relative source energy requirements.

Source energy accounting is useful for allocating research and development efforts for developing new energy supplies. The assumption of severe relative price distortion implies that source energy as well as prices must be considered in selecting the energy source for a given use. Little previous work has been done to assess relative price distortions. The studies reviewed in the Appendix indicate that price distortion is probabiy relativeiy minor. In any case, no thermodynamic method of comparing aiternative mixes of energy resource use has gained acceptance (Long 1978).

The usefuiness and methodology of energy anaiysis have been subject to considerable debate, including several international and national conferences. (a) Currently, the debate centers on three primary issues: 1) the

(a) See Long 1978; International Federation of Institutes for Advanced Study 1975; Institute for Gas Technology 1975; and Instutite for Energy Studies 1975. 
usefulness of energy analysis as a policy input; 2) comparisons of Btu from different sources; and 3) the appropriate boundaries for analysis. The resolution of any one of these issues is interrelated with resolution of the others.

The debate over the usefulness of energy analysis covers a spectrum of positions, including that energy analysis 1) should replace economics (Odum 1972); 2) provides a means of assessing factor substitution and technological change (Long 1978; Maddox 1978); and 3) is virtually useless (Berry, Heal and Salamon 1977). Except for those who ascribe to an energy theory of value, a consensus has developed that energy analysis cannot be used as the basis for allocating energy resources or selecting fuel types. (a) There is no physical or thermodynamic basis for converting from one energy source to another that accounts for the inherent qualitative differences. Even if there were a way of converting all sources to an equivalent Btu value, there would still be the problem of determining what mix of energy, labor and capital should be applied to produce some good, such as space heat. In fact, it has been demonstrated that use of energy content to allocate resources would result in lower levels of production (Huettner 1978; Berry, Heal and Salamon 1977). A criterion of minimizing source energy consumption would suggest policies, such as maximizing imports of foreign oil or designing buildings that do not use fuels in spite of the impacts that would result on the economy, non-energy resources and personal comfort.

Energy analysis, however, is useful for 1) assessing opportunities for technical substitution and technological change (e.g., methanol use in automobiles); and 2) estimating total impacts of a given energy end use. Even in these cases energy analysis does not supplant economic analysis, but supplements it. Of most importance for this paper, energy analysis provides a means for assigning the impacts associated with a process to the end use of the energy processed. For example, the acres of strip-mined land associated with using coal-generated electricity for space heating can be assessed by tracing the amount of coal at mine mouth used to supply the space heat. Energy analysis

(a) See Long 1978; Maddox 1978; and Berry, Heal and Salamon 1977. 
is a method of tracing energy from a given end use to the natural resources and, thus, provides an accounting of the resources required to support that end use (Fraley, McDonald and Carter 1978). Detailed accountings of resource use for alternative end uses and energy supply trajectories are available in published form. ${ }^{(a)}$

The issues of comparability of Btu and boundaries of analysis are largely moot, though unresolved (Fraley, McDonald and Carter 1978). Analysts have, by and large, accepted the role of energy analysis as described above and, thus have provided alternative estimates of total Btu use as well as the breakdown of Btu by resource type. In most analyses, the boundary issues have been consistently resolved by 1 ) including all indirect energy inputs as calculated by an input-output model of energy flows in the economy; and 2) providing an accounting based on the total resource in the ground and the resource at the mine mouth $\left(E_{6}\right.$ and $E_{5}$ in Figure 10 , respectively). Boundary issues arose because some early analyses provided conflicting estimates of the energy yields of solar and nuclear energy supply trajectories. Subsequent analysis has shown that the quantities of indirect energy are generally very sma11 (Herendeen 1978; Rotty, Perry and Reister 1973), although some new technologies seem to have very significant indirect energy inputs (e.g., the gas heat pump, (b) methanol from grain and solar satellites) (Herendeen 1978). These indirect inputs could be expected to decline sharply as the technology improves enough to become commercial (Vogenthaleter 1976).

Despite the controversy surrounding energy analysis, a consensus has developed that it provides a useful means of assessing the resource requirements of an energy supply trajectory. Several detailed estimates for many end use supply trajectories have been made for both the total in ground resource and the mine mouth resource. ${ }^{(c)}$

(a) See Fabretti et al. 1975; Fabretti 1977; Development Sciences, Inc. 1977; and Vogenthaleter 1976.

(b) See Fabretti et al. 1975; Fabretti 1977; and Development Sciences Inc. 1977.

(c) See Fabretti et al. 1975; Fabretti 1977; Development Sciences, Inc. 1977; Vogenthaleter 1976; and Rotty, Perry and Reister 1975. 
$\underline{\text { RUF'S }}$

ASHRAE has proposed that a RUF, defined as $\frac{\text { resources consumed }}{\text { energy delivered }}$, be used as a multiplier of Btu at the building boundary. The RUF multiplier converts site-based Btu into units of the fuel source at the wellhead or mine mouth. While some fuel losses are accounted for in this manner, a means of assessing the relative value of both the losses and the types of energy available at end use points is lacking. It was partly in response to this failing of RUF's that the use of RIF's was proposed.

$\underline{\text { RIF's }}$

In ASHRAE Standard 9075R, a RIF is defined as a multiplier which permits quantitative evaluation of resource choices and accounts for social, economic, environmental and national interest issues. Unfortunately, physical quantitybased multipliers do not provide a means of trading off energy savings against capital investment in energy saving features.

As an alternative Weber (1977) suggested a multiplier that would convert the private market price of a fuel to a social price. This multiplier is obtained from division of an estimate of social cost by market price. The use of a RIF defined as the ratio of social cost to market price has drawbacks as well if it is lifted from the context of life cycle cost minimization. If such a RIF is applied to design energy consumption, at the building boundary e.g., Btu/sq ft/yr $\times$ RUF $\times$ RIF, the results are undesirable. To illustrate the problem, let us assume that two fuels have the same RUF value but different prices and social costs. The RIF values are derived from the ratio of social cost to price.

$$
\begin{array}{lll}
\text { RUF }_{1}=1.5 & \text { Price }_{1}=\$ .25 / \text { unit } & \text { Social Cost } \\
\text { RUF }_{2}=1.5 & \text { Price }_{2}=\$ .10 / \text { unit } & \text { Social Cost } \\
2 & =\$ .20 / \text { unit }
\end{array}
$$

With building boundary energy use of 30 units for example, the use of these RIF values leads to design energy budgets as follows:

$$
\begin{aligned}
\mathrm{DEB}_{1} & =\mathrm{Btu} \times \mathrm{RUF}_{1} \times \mathrm{RIF}_{1} \\
& =30 \times 1.5 \times \frac{.30}{.25} \\
\mathrm{DEB}_{1} & =54 \text { resource units }
\end{aligned}
$$




$$
\begin{aligned}
D_{2 E B_{2}} & =B t u \times R_{2} \times R_{2} I F_{2} \\
& =30 \times 1.5 \times \frac{.20}{.1} \\
D^{-1} B_{2} & =90 \text { resource units }
\end{aligned}
$$

If resource units are minimized, fuel \#1 wi1l be chosen over fuel \#2. Selection of fuel \#1 on this basis would result in fifty percent higher social costs per energy unit delivered than would occur using fuel \#2. A design energy budget based on such an approach favors the fuels for which distortion between market price and social cost is lowest, but not necessarily the fuel for which the total social cost is lowest.

SOCIAL COSTS

As a result it appears that the best alternative for development of an energy budget is the use of total social costs or a proxy such as the marginal cost of new energy supplies in life cycle cost minimization. Both the value of nonmarket effects and energy losses could be accounted for by the total social costs associated with use of a fuel. A comparison of the various concepts suggested to incorporate energy losses and social costs is

\begin{tabular}{|c|c|c|}
\hline \multirow[b]{2}{*}{ Actors } & \multicolumn{2}{|c|}{ Formulations } \\
\hline & RUF & RIF \\
\hline ASHRAE & RUF $=\frac{\text { Resources Consumed }}{\text { Energy Delivered }}$ & Undeveloped \\
\hline ADL (1978) & Same as ASHRAE & Undeveloped \\
\hline Weber (1978) & Unnecessary & RIF $=\frac{\text { Social Price }}{\text { Effective Price(J) }}$ \\
\hline $\begin{array}{l}\text { BNw (present } \\
\text { study) }\end{array}$ & Unnecessary & $\begin{array}{l}\text { Social cost = Marginal market cost } \\
\text { plus (nonmarket costs } x \text { conversion } \\
\text { efficiency factors) }\end{array}$ \\
\hline
\end{tabular}
given in Tabie 4.

\section{TABLE 4. Comparison of RUF and RIF Conceptualizations}

Use
Site Btu $\times$ RUF $\times$ RIF
Site Btu $\times$ RUF with
result converted to Btu
Price $\times$ RIF in life cycle
cost minimization
Site Btu $\times$ Social Cost in
life cycle cost minimization

(a) Market price per $10^{6}$ Btu. 
In order to estimate the value of the social costs for a fuel it is necessary to combine the nonmarket costs shown in Figure 8 with the energy losses at each stage of the fuel supply trajectory shown in Figure 10 . From this information, the total nonmarket costs per Btu (at the building boundary) can be calculated and then added to the marginal market cost of new production of that fuel to provide estimates of the total cost to society per Btu of increased use of that fuel. The development of social cost estimates requires the use of fuel conversion efficiency factors which account for the energy losses in the fuel supply trajectory. These technical efficiency factors are calculated for each stage of the fuel conversion process in which significant energy losses occur. In Figure 10 the technical efficiency factor for a process step $P_{i}$ would be $\frac{E_{i-1}}{E_{j}}$. When the reciprocal of the technical efficiency factor for a process activity is multiplied by the nonmarket cost per Btu input to that activity the nonmarket cost associated with the Btu lost in processing is spread onto the remaining Btu, so that all of the social costs incurred are borne by the end user.

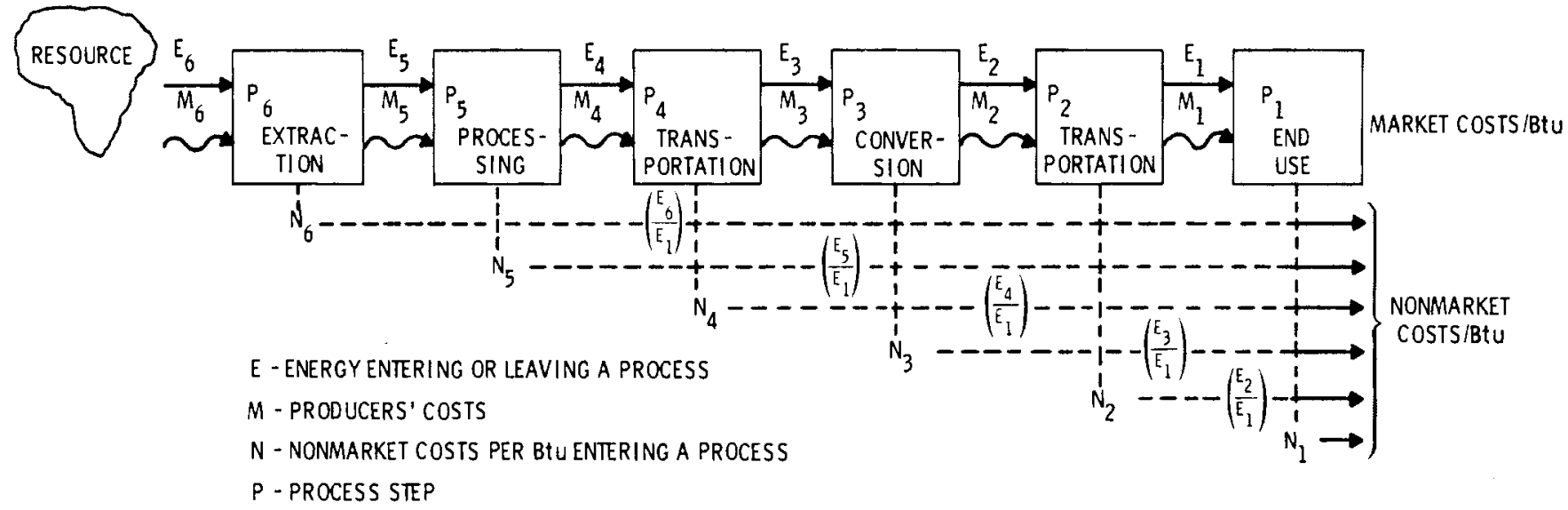

FIGURE 11. Aggregation of Social Cost per End Use Btu

This procedure is diagrammed in Figure 11 . The nonmarket costs per Btu at each stage of production are converted into the equivalent cost per end use Btu. Summing $a 11$ of the estimated market and nonmarket costs per Btu at the building boundary places the energy losses and social costs associated with 
various energy sources on a consistent basis. These estimates of social cost per end use Btu can then be used in life cycle cost minimization to identify the optimal level of energy consumption. 


\section{CONCLUSIONS}

Based on the preceding discussion of the fuel market, social costs of resources and the need for a criterion to value building energy system design tradeoffs so that life cycle costs are minimized, the following conclusions can be drawn.

1. Accurate valuation of both inputs and outputs is crucial in achieving economic efficiency in resource allocation.

2. While fuel prices still do not capture the full social cost of a fuel, the documentable differences between the market price and social cost per Btu of fuels appear to have been declining since the mid-1960s.

3. Thermodynamic efficiency alone is not a sufficient criterion for determining optimal energy consumption levels and design tradeoffs in buildings.

4. Use of a RIF $x$ RUF multiplication of a design energy budget does not lead to choice of the fuel with the lowest social cost per end use Btu.

5. The optimal level of fuel consumption in a building may be determined through use of life cycle cost minimization incorporating the true relative costs of all inputs to the building space conditioning and lighting system.

6. The most appropriate fuel costs for use in the life cycle cost model are estimates of marginal social costs.

7. An accurate estimation of marginal social costs will incorporate energy loss considerations in the computations.

8. Estimation of nonmarket cost components (externalities) of social cost would be costly and subject to a high degree of uncertainty.

9. If estimation of marginal social costs is judged unfeasible, the best proxy is an estimate of marginal market costs. 


\section{REFERENCES}

Adelman, M. A. 1964. "Efficiency of Resource Use in Crude Petroleum." Southern Economic Journal, October 1964, pp. 101-122.

Anderson, R. J., Jr. and T. D. Crocker. 1970. Air Pollution and Housing: Some Findings. Paper No. 264, Krannert Graduate School of Industrial Administration, Purdue University, Lafayette, Indiana.

ADL 1978. See Lentz 1978.

American Society of Heating, Refrigeration and Air Conditioning Engineers. Proposed Standard 90-75R. ASHRAE, Louisville, Kentucky.

Berry, R. S., G. Heal and P. Salamon. 1977. On a Relation Between Economic and Thermodynamic Options. Working paper, University of Chicago, Chicago, ITlinois.

Brannon, G. M. 1974. Energy Taxes and Subsidies. Ballinger Publishing, Cambridge, Massachusetts.

Breyer, S. G. and P. W. MacAvoy. 1974. Energy Regulation by the Federal Power Commission. The Brookings Institution, Washington, DC.

Burrows, J. and T. Domenich. 1970. An Analysis of the United States on Import Quota. Lexington Books, Lexington, Massachusetts.

Cabinet Task Force on 0i] Import Control. 1970. The 0il Import Question. Government Printing Office, Washington, DC.

Coal Traffic Annual. 1973. National Coal Association, Washington, DC.

Cone, B. W., et al. 1978. An Analysis of Federal Incentives Used to Stimulate Energy Production. PNL-2410, Pacific Northwest Laboratory, Richland, Washington.

Cox, J. C. and A. W. Wright. 1978. "The Effects of Crude $0 i 1$ Price Controls, Entitlements and Taxes on Refined Product Prices and Energy Independence." Land Economics. 54(1):1-15.

Dahl, A. J. 1976. "Deregulation of Natural Gas at an Impasse." Public Utilities Fortnightly. October 21, 1976.

Development Sciences, Inc. 1977. Using Net Energy Methodology for Energy Planning: Tradeoffs Versus End Use Technologies. Development Sciences, Inc., East Sandwich, Massachusetts. 
Dials, G. E. and E. C. Moore. 1974. "The Cost of Coal." Environment. $16(7): 18-37$.

Duchesneau, T. D. 1974. Competition in the U.S. Energy Industry. Ballinger Publishing, Cambridge, Massachusetts.

Environmental Protection Agency. 1973. Assessing the Social Impacts of 0il Spills. Proceedings of an Invitational Symposium. Rensselaerville, New York, September 1973.

Erickson, E. W. and R. M. Spann. 1971. "Supply Response in a Regulated Industry: The Case of Natural Gas." The Bell Journal of Economics and Management Science. 2(1):94-121.

Fraley, D. W., C. L. McDonald and N. E. Carter. 1978. A Review of Issues and Applications of Net Energy Analysis. PNL-SA-6619, Pacific Northwest Laboratory, Richland, Washington.

Fabretti, A. J., Jr. et a1. 1975. A Study to Develop Energy Estimates of Merit for Selected Fuel Technologies. Development Sciences, Inc., East Sandwich, Massachusetts. Available from NTIS, Report No. PB-249-994.

Fabretti, A. J., Jr. 1977. Application of Net Energy Analys is to Consumer Technologies. Development Sciences, Inc., East Sandwich, Massachusetts.

Forbes Magazine. "Who's Where in Profitability." January 1, 1975, p. 18.

Foster Associates, Inc. 1973. The Impact of Deregulation on Natural Gas Prices. Report for the American Petroleum Institute, Washington, DC.

Friedlaender, A. 1969. The Dilemma of Freight Transport Regulation. The Brookings Institution, Washington, DC.

Friedlander, A. 1971. "The Social Costs of Regulating the Railroad." The American Economic Review. LX(2):226-234.

Garret, R. 1970. "The Effects of Prices on Future Natural Gas Supplies." Paper presented at The Potential Gas Agency Meeting,. Colorado Springs, Colorado, October 28, 1970.

Green, M. J. 1972. The Closed Enterprise System. Grossman Publishers, New York, New York.

Harberger, A. C. 1954. "Monopoly and Resource Allocation." in American Economic Review, Papers and Proceedings. Vol. XLIV, No. 2, May 1954.

Helms, R. B. 1974. Natural Gas Regulation, An Evaluation of FPC Price Controls. American Enterprise Institute, Washington, DC. 
Herendeen, R. A. 1978. "Energy Analys is of Two Technologies: Gasahol and Solar Satellite Power Station." presented at the Energy Modeling and Net Energy Analys is Symposium, Colorado Springs, Colorado, August 21-25, 1978. Sponsored by the Institute of Gas Technology, Chicago, Illinois.

Holcombe, R. G. 1974. The Economic Impact of an Interruption in United States Petroleum Imports. AD-A010-914, National Technical Information Service, Springfield, Virginia.

Howard, H. A. 1977. "A Measurement of the External Diseconomies Associated with Bituminous Coal Surface Mining: Eastern Kentucky, 1962-1967. Natural Resources Journal. III:76-101, January 1977.

Heuttner, D. 1978. "Energy Analysis and U1timate Limits." presented at the Energy Modeling and Net Energy Analys is Symposium, Colorado Springs, Colorado, August 21-25, 1978. Sponsored by the Institute of Gas Technology, Chicago, Illinois.

Institute for Energy Studies. 1975. NSF-Stanford Workshop on Net Energy Analysis. Stanford University and TRW System Group, Palo Alto, California.

International Federation of Institutes for Advanced Study. 1975. Workshop on Energy Analysis and Economics: Findings. Report No. 9, IFIAS, Sweden.

Institute for Gas Technology. 1978. Symposium Papers: Energy Modeling and Net Energy Analysis. Held August 21-25, 1978, Colorado Springs, Colorado. Sponsored by IGT, Chicago, IIlinois.

Ives, E. E. and M. L. Holloway. 1977. Natural Gas Pricing: An Economic Analys is of New Gas Price Deregulation with Emphasis on the Interstate and Texas Intrastate Markets. Executive Summary. Texas Governor's Advisory Council, Austin, Texas.

Kitch, E. W. 1958. "Regulation of the Field Market for Natural Gas." Journal of Law and Economics. 11:243-281.

Khazzoom, J. D. 1971. "The FPC Staff's Econometric Model of the Natural Gas Supply in the United States." The Bell Journal of Economics and Management Science. 2(1):51-93.

Kumins, L. 1974. Economic Impact Report on Deregulation of Natural Gas. Economics Division, Congressional Research Service, Library of Congress, Washington, DC. Prepared for the Honorable John E. Moss, Chairman, House Committee on Commerce and Finance.

Lee, M. 1974. State/Federal Regulation of Natural Gas. L/R-7, National Science Foundation. Available from NTIS, Springfield, Virginia.

Lentz, C. 1978. "RUF and Energy Conservation." ASHRAE Journal. June 1978, pp. $34-41$. 
Lipsey, R. G. and K. Lancaster. 1956-57. Rev. Econ. Stud. 25 (63):11-32.

Long, T. V., II. 1978. "Comparing Methods of Energy Analys is in an Economic Framework." Presented at the Energy Modeling and Net Energy Analys is Symposium, Colorado Springs, Colorado, August 21-25, 1978. Sponsored by the Institute of Gas Technology.

MacAvoy, P. W. 1962. Price Formation in Natural Gas Fields. Yale University Press, New Haven, Connecticut.

MacAvoy, P. W. 1970. "The Rationale for Regulation of Gas Field Prices." in The Crisis of the Regulatory Commissions. P. W. MacAvoy, editor. W. W. Norton, New York, New York.

MacAvoy, P. W. 1971. "The Regulation-Induced Shortage of Natural Gas." Journal of Law and Economics. 14(1):167-199.

MacAvoy, P. W., ed. 1977. Federal Energy Administration Regulation. American Enterprise Institute, Washington, DC.

MacAvoy, P. W. and R. S. Pindyck. 1973. "Alternative Regulatory Policies for Dealing with the Natural Gas Shortage." The Bell Journal of Economics and Management Science. 4(2):454-498.

MacAvoy, P. W. and R. S. Pindyck. 1975a. The Economics of the Natural Gas Shortage. North Holland Publishing, Amsterdam.

MacAvoy, P. W. and R. S. Pindyck. 1975b. Price Controls and the Natural Gas Shortage. American Enterprise Institute, Washington, DC.

Maddox, K. 1978. "Energy Analysis and Resource Substitution." presented at the Energy Modeling and Net Energy Analysis Symposium, Colorado Springs, Colorado, August 21-25, 1978. Sponsored by the Institute of Gas Technology, Chicago, Illinois.

Marchand, D. J. and R. Sorensen. 1977. "Has Electricity Regulation Resulted in Higher Prices? Comment." Economic Inquiry. XV (4):610-612, October 1977.

McDonald, S. L. 1976a. "Taxation System and Market Distortion." Energy Supply and Government Policy. R. J. Kaller and W. A. Vogely, eds. Cornell University Press, I thaca, New York.

McDonald, S. L. 1976b. "U.S. Depletion Policy: Some Changes and Likely Effects." Energy Policy. 4(1):56-63.

Mead, W. J. 1976. "Petroleum: An Unregulated Industry?" Energy Supply and Government Policy. R. J. Kaller and W. A. Vogely, eds. Cornell University Press, I thaca, New York. 
Mitche11, E. J. 1974. U.S. Energy Policy: A Primer. American Enterprise Institute for Public Policy Research, Washington, DC.

Moore, C. G. 1975. "Has Electricity Regulation Resulted in Higher Prices? An Econometric Evaluation for Utilizing a Calibrated Regulatory Input Variable." Economic Inquiry. 13(3):207-220, June 1975.

Moore, T. G. 1972. Freight Transportation Regulation. American Enterprise Institute, Washington, DC.

Moore, T. G. 1975. "Deregulating Surface Freight Transportation." In Promoting Competition in Regulated Markets. A. Phillips, ed. The Brookings Institution, Washington, DC.

North, W. D. and M. W. Merkhofer. 1975. "Analysis of Alternative Emissions Control Strategies." Air Quality and Stationary Source Emission Control. National Academy of Sciences, Washington, DC.

Odum, H. T. 1972. Environment Power and Society. John Wiley \& Sons, New York, New York.

Pindyck, R. S. 1974. "The Regulatory Implications of Three Alternative Supply Models of Natural Gas." The Bell Journal of Economics and Management Science. $5(2): 633-645$.

Randa11, A., et al. 1978. Estimating Environmental Damages from Surface Mining of Coal in Appalachia: A Case Study. Environmental Protection Technology Series, EPA-600/2-78-003. Environmental Protection Agency, Washington, $D C$.

Rotty, R. M., A. M. Perry and D. B. Reister. 1973. Net Energy from Nuclear Power. IEA-75-3, Institute for Energy Analysis, Oak Ridge, Tennessee.

Sagan, L. A. 1974. "Health Costs Associated with the Mining, Transport and Combustion of Coal in the Steam-Electric Industry." Nature 250:107-111, July 12, 1974.

Salmon, R. C. 1970. Systems Analysis of the Effects of Air Pollution on Materials. Midwest Research Institute, Kansas City, Missouri.

Sharefkin, M. 1974. The Economic and Environmental Benefits from Improving Electrical Rate Structures. EPA-600, U.S. Environmental Protection Agency, Washington, DC.

Stigler, G. J. and C. Friedland. 1962. "What Can Regulators Regulate? The Case of Electricity." Journal of Law and Economics. 4:1-16, October 1962.

Sunder, S. 1977. 0il Industry Profits. American Enterprise Institute, Washington, DC. 
U.S. Atomic Energy Commission. 1974. Comparative Risk-Cost-Benefit Study of Al ternative Sources of Electrical Energy. WASH-1224. U.S. AEC, U.S. Government Printing Office, Washington, DC.

U.S. Bureau of the Census. 1976. Statistical Abstracts of the United States. 97 th edition, Bureau of the Census, Washington, DC.

U.S. Federal Energy Administration. 1974. Project Independence Report. FEA, U.S. Government Printing Office, Washington, DC.

U.S. Federal Energy Administration. 1976. National Energy Outlook. FEA, U.S. Government Printing Office, Washington, DC.

U.S. Federal Power Commission. 1975. A Preliminary Evaluation of the Cost of Natural Gas Deregulation. Report of the FPC Intra-agency Task Force. Federal Power Commission, Washington, DC.

U.S. Federal Trade Commission. 1973. Preliminary Federal Trade Commission Staff Report on its Investigation of the Petroleum Industry. FTC, Washington, DC.

U.S. Senate, Committee on the Judiciary. 1973. The Industrial Reorganization Act. Pt. 1. General View and Hearings before the Subcommittee on Antitrust and Monopoly, 93rd Congress, 1st session.

U.S. Senate, Committee on the Judiciary. 1975. The Petroleum Industry Pts 1, 2 and 3. Hearings Before the Subcommittee on Antitrust and Monopoly, 94th Congress, lst session.

Vogenthaleter, T. J. et a1. 1976. Net Energy Analysis: An Energy Balance Study of Fossil Fuel Resources. Colorado Energy Research Institute, Golden, Colorado.

Weber, S. F. 1977. The Effect of "Resource Impact Factors" on Energy Conservation Standards for Buildings. NBSIR 77-1199, National Bureau of Standards, Washington, DC.

Weber, S. F. 1978. The Effect of "Resource Impact Factors" on Energy Conservation Standards for Buildings. NBS Building Science Series \#114, Nationa Bureau of Standards, Washington, DC.

Worcester, D. A. Jr. 1973. "New Estimates of the Welfare Loss to Monopoly: United States 1956-1969." The Southern Economic Journal. XL(2). 
APPENDIX A

ANNOTATED BIBLIOGRAPHY 


\section{ANNOTATED BIBLIOGRAPHY}

The appendix contains an annotated bibliography of studies relevant to empirical estimation of the social costs of fuels. 
Study \# 1

Fuel: A11 Distortion: Environmental Damage

Study: Battelle Columbus Laboratories. 1973. Environmental Consideration In Future Energy Growth. PB-239157, Available from National Technical Information Service, Springfield, Virginia.

Scope: This is a broad survey of the environmental effects of energy production.

Comments: Control costs are quantified - social costs are not. This and similar studies could be used as sources of information on the physical effects for which values must be estimated.

Study \# 2

Fuel: Coal, Nuclear Distortion: Environmental, Health

Study: Bernardi, R. and B. Borko. 1975. Quantitative Environmental Comparison of Coal and Nuclear Generation Workshop Summary. Mitre Corp. PB-248-651, Available from National Technical Information Service, Springfield, Virginia.

Scope: A Stanford Research Institute paper was presented and discussion centered on assessment of public risks from coal and nuclear fuel cycles.

Method: Nuclear cycle social costs are based on probability estimates of damages.

Findings: Social Costs of coal (p. 17) excluding sulfur oxide emissions $0.56 \mathrm{mi11 \textrm {s } / \mathrm { kWh }}$

Sulfur Cost in Mills/kWh

Low $\underline{\text { High }}$

$\begin{array}{llll}\text { Urban } & 3.1 & 11.5 & \begin{array}{l}\text { External costs of the nuclear } \\ \text { fuel cycle were estimated to }\end{array} \\ \text { Rural } & 1.3 & 4.1 & \text { be } 0.06 \mathrm{mills} / \mathrm{kWh} .\end{array}$


Study \# 3

Fuel: $\quad 0 i 1 \quad$ Distortion: Taxes

Study: Brannon, G. M. 1974. Energy Taxes and Subsidies. Ballinger Publishing Corp., Cambridge, Massachusetts.

Scope and Method:

Comprehensive analysis of the taxation and subsidies applicable to fuels and energy sources. Particularly oil and natural gas. The author compares the results under a present (early 1970s) tax system with the likely outcome under a market system. Discusses various price distortions in Energy Markets and the effects of taxes on correcting or exacerbating the problem.

Findings: 1. Depletion allowance works unevenly among various sources. It helps oil and gas significantly.

2. The effect of these tax benefits has been $50 \%$ to lower price, $40 \%$ to higher royalties and $10 \%$ higher profits.

3. Tax provisions relating to foreign credit have resulted in significant benefits to oil companies

4. If all savings from tax provisions were passed along to consumers the final price reduction would be:

$\begin{array}{lr}0 i 1 & 13.2 \% \\ \text { Natural Gas } & 11.5 \% \\ \text { Coal } & 3.4 \% \\ \text { Uranium } & 2.8 \%\end{array}$

Comments: Even 1974 information is old. The tax laws have been substantially changed. These estimates are likely too high in light of the 1975 tax revision. 
Study 4

Fuel: $\quad$ Natural Gas

Distortion: Regulation

Study: Breyer, G. and Paul W. MacAvoy. 1974. Energy Regulation by the Federal Power Commission. Brookings Institution, Washington, $\overline{\mathrm{DC}}$.

Scope and

Method: Breyer and MacAvoy use an updated version of their econometric model of the natural gas industry to evaluate the effectiveness of the F.P.C. to control the wellhead price of gas and to regulate natural gas pipelines and the production of electricity.

Findings: By estimating the market clearing price and predicting the effect of that price on future supplies, the authors predict new reserves would have been three times greater and immediate production twice as great if there had been no wellhead price controls. The authors provide estimates of the costs of F.P.C. regulation (P. 123) and evidence of the presence of shortages (P. 73).

Comments: This "improved" model incorporates a variety of econometric techniques to upgrade a model that has been developed over a number of years. 
Study 5

Fuel: $\quad$ Gas, $0 i 1$, Coal, Electricity

Distortion: Health Effects and Fuel Conversion Costs

Study: Cohen, A. S., G. Fishelson and J. L. Gardner. 1974. Residential Fuel Policy and the Environment. Ballinger Publishing Co., Cambridge, Massachusetts.

Scope: The costs and benefits of policies which would encourage space heating with electricity and gas rather than coal and oil are considered for Chicago.

Method: Social costs are estimated using various fuel price assumptions and the cost of furnace conversion. Benefits are estimated both from property value differences related to air quality and from assumed income and consumption expenditure effects of reduced particulates and sulfur dioxide.

Findings: $A$ coal and oil ban was found to maximize net benefits.

Comments: This study purports to estimate willingness-to-pay for air quality but does not actualiy do so. The conclusions and discussion of social cost assume that the subject has been treated comprehensively when in fact it has not. 
Study $\# 6$

Fuel: $\quad$ 0il, Natural Gas, Distortion: Taxation, Subsidies Hydro, Nuclear, Coal

Study: Cone, B. W., et a1. 1978. An Analysis of Federal Incentives Used to Stimulate Energy Production. PNL-2410, Pacific Northwest Laboratory, Richland, Washington.

Scope and

Method: The goal of the study is an analysis of past federal energy incentive programs with a view to recommending appropriate action by the federal government toward solar energy. The approach is interdisciplinary including a variety of viewpoints of the effects of such incentive programs.

Findings: Attempts were not made to estimate the pricing distortions of separate taxation and subsidy policies. It does conclude incentives have played a large role in shaping present energy prices and usage and it does estimate to size of these incentives.

Comments: Provides historical and quantitative descriptions of federal policies toward various energy sources including nuclear, hydro, coal, petroleum, and natural gas.

Study $\# \underline{6 A}$

Fuel: $\operatorname{Coa} 1 \quad$ Distortion: Environmental Damage

Study: Cooperative Wildlife Research Laboratory, Southern Illinois University. 1977. Illinois Lands Affected by Underground Mining for Coal. Illinois Institute for Environmental Quality, Chicago, Illinois.

Scope and

Method: Lands affected by underground mining were surveyed during 1975-76 to ascertain location, ownership, and environmental damages.

Findings: Of the more than 4,000 sites surveyed over $1 / 3$ showed no evidence of environmental damage. Three fourths of the damaged land had been associated with the mining operations of major companies.

Comments: Contains detailed data on vegetation and water and soil chemistry. 
Study \# 7

Fuel: $\quad 0$ i1 $\quad$ Distortion: Taxes

Study: Cox, J. C. and A. W. Wright. 1978. "The Effects of Crude 0i1 Price Controls, Entitlements and Taxes on Refined Product Prices and Energy Independence," Land Economics 54(1):1-15.

Scope and Method:

Theoretical analysis of the effects of price controls and entitlements on the retail price of gasoline. The authors analyze the effect these programs have had on crude $0 i 1$ costs of a representative refiner. These effects are analyzed under the Energy Policy and Conservation Act of 1975 and Emergency Petroleum Allocation Act of 1973 .

Findings: Under both the above acts, refiner's total average and marginal costs have been reduced. This has reduced consumer prices. (With the exception of products where prices are determined by perfectly elastic supplies, for instance residual fuel oil.) While the acts have increased independence in most products it has been reduced for crude 0i1. Crude oil prices have been reduced by an import subsidy.

Comments: Al1 products have had lower prices as a result of current controls and entitlements but no estimate of the magnitude of the reduction is provided. Indeed, no analysis is given of the cost increasing effects of regulations. This would work in the opposite direction of any price reduction generated by the E.P.C.A. 
Study 8

Fuel: Natural Gas Distortion: Regulation

Study: Dahl, A. J. 1976. "Deregulation of Natural Gas at a Political Impasse." Public Utilities Fortnightly. October 21, 1976, pp. 24-32.

Scope and

Method:

Dahl discusses the history of Federal Power Commission regulation of natural gas. He analyzes the results of the regulation particularly trends in production and consumption with the resulting shortage, and he estimates the free market price by comparing Btu's of gas with those of furnace oil.

Findings: Information is provided on curtailments ( $p .28$ ). Dahl notes that 14 of 42 pipelines predicted shortages of 20 percent for the winter of 1975-76. The estimate of the "free market" price of interstate gas would be $\$ 1.50 / \operatorname{Mcf}(p .30)$ (given in 1976 dollars?). The price of gas in unregulated intrastate markets is $\$ 1.50-\$ 2.00 /$ Mcf.

Comments: The method of predicting the "free market price" of gas on BTu comparisons with furnace oil assumes no major distortions in furnace oil and that the sole reason for choosing a fuel is cost per Btu and not cleanliness, supplv certainty or some other attribute. 
Study $\#$ 9

Fuel: Coal

Distortion: Environment and Health

Study: Dials, G. E. and E. C. Moore 1974. "The Cost of Coal". Environment, $16(17): 18$.

Scope: Deepmining: mine fires, disposal of mine wastes, acid mine drainage, subsidence, accidents, black lung disease.

Surface-mining: reclamation, acid mine drainage, sedimentation, loss of recreation value of land, accidents.

Method: Assumptions - total U. S. coal production between 1970 - 2000 will be 20 billion tons; $60 \%$ will be surface and $40 \%$ deepmined; no significant technological change; no significant legislation change. The cost estimates are generally linear extrapolations of past experience. Costs internalized by the coal companies are excluded.

Findings: Average social cost during 1970 - 2000 will total $\$ 0.8727 /$ ton for deep-mined and $\$ 1.0028 /$ ton for surface-mined coal. Costs: fires $=\$ 0$; waste disposal $=\$ 0.07 /$ ton; acid mine drainage $=\$ .06$ to $\$ .20 /$ ton; subsidence $=\$ .50 /$ ton; accidents $=\$ .086 /$ ton .

Comments: Accident costs are very conservatively estimated. Occupational disease and accidents are the only health effects considered. 
Study \# 10

Fue1: $\quad 0 i 1$, Uranium, Natural Distortion: Monopoly

Gas, Coal

Study: Duchesneau, T. D. 1975. Competition in the U.S. Energy Industry. Ballinger Publishing, Cambridge, Massachusetts.

Scope and

Method: Duchesneau provides an extensive investigation of the structure, conduct and performance of energy markets. Examining the size of concentration ratios and entry conditions reveals the impact of structure on competition. Information is provided on prices, technological progress and profits and used to evaluate performance and conduct in the energy markets.

Findings: Levels of seller concentration are not extraordinarily high but have been increasing. Scale economies do not appear to create entry barriers. Competition has been reduced by government programs, especially oil imports and demand prorationing. Concludes the structure of the energy industry, with the exception of uranium is not monopolistic.

Comments: Source of a vast amount of data and information on structure of nearly all energy markets. Appendix contains eight additional studies of competition in specific energy markets 
Study 11

Fuel: $\quad 0 i 1 \quad$ Distortion: Environment

Study: Environmental Protection Agency, 1973. Assessing the Social Impacts of 0 il Spills. Proceedings of an Invitational Symposium, Rensselaerville, NY, September 1973.

Scope: This is a broad assessment of economic, environmental, and political aspects of $0 i 1$ spill management.

Method: This was a symposium assessing the state-of-the-art in oil spill damage management and value estimation.

Findings: Cost of oil cleanup - $\$ 0.50$ to $\$ 14 /$ gallon. Damage estimates for spills between 1953 and 1972 are summarized but there is no consistent basis for comparison of values.

Comments: The values quoted are too inconsistent to be useful. 
Study \# 12

Fuel: Natural Gas Distortion: Regulation

Study: Erickson, E. W. and R. M. Spann. 1971. "Supply Response in a Regulated Industry: The Case of Natural Gas." The Bell Journal of Economics and Management Science. 2(1):94-121.

Scope and

Method: Provides a model of the natural gas industry combining cross sectional and time series data. Examines wildcat wells, the ratio of successful to total wildcats, average crude oil discovery size per successful wildcat and average natural gas discovery site, with regression equations for each.

Findings: The following quotation provides a description of their free market price: "If the elasticity of supply of new discoveries is about +0.5 and if the relative real shotage, expressed as a percent of current production is 10 to 25 percent, then the percentage increase in the average wellhead price of natural gas is 20 to 50 percent." (P. 119)

Comments: Comparison of this natural gas model with two others is provided in Pindyck's 1974 Bell Journal article. 
Study \# $\quad 13$

Fuel: Natural Gas Distortion: Regulation

Study: Federal Power Commission. 1975. A Preliminary Evaluation of the Cost of Natural Gas Deregulation. Interagency Task Force, FPC, Washington, DC.

Scope and

Method: The report analyzes the net cost to consumers of various deregulation proposals. Using different sets of parameters (i.e., demand and supply elasticities etc.), estimates of the increased payments to producers are considered costs and benefits are the additional natural gas replacing more expensive alternative fuels. In addition, a variety of other studies of gas deregulation are reviewed.

Findings: In order to estimate the costs of deregulation the F.P.C. predicted the market clearing price. They provide a range of alternative estimates of the deregulated price from about $\$ .82 / \mathrm{Mcf}$ to $\$ 1.49 / \mathrm{Mcf}$.

Comments: Their reviewed studies also provide estimates of the free market price. These estimates range from $\$ .75 /$ licf to $\$ 1.75 /$ Mcf. 
Study

14

Fuel: Electricity-Coal Distortion: Transportation Regulation

Study: Friedlaender, A. F. 1969. The Dilemma of Freight Transport Regulation. The Brookings Institution, Washington, D.C.

Scope and

Method:

Friedlaender presents a lengthy discussion of the history, rationale and structure of I.C.C. regulation. She estimates the marginal costs for freight transportation by various modes as well as estimates of the deviations of regulated price to optimal price and estimates of the losses as a percentage of revenue for five product classifications as well as a total for all commodities.

Findings: The deviation of a regulated price from optimal price is smallest for mining products, about $6 \%$. The optimal price in this case being out-of-pocket costs as an estimate of marginal costs. Her belief is that coal shipping rates are fairly close to costs. Since coal is competitive with a variety of other fuel sources and transportation costs are a very important segment of the final price of coal, a significant deviation of rates from costs would decrease shipments of coal to an extent that would harm the railroads.

Comments: This book serves as a basis for many of the other studies of transportation regulation. It contains a large amount of information on shipping modes as well as a large amount of source material. 
Study \# 15

Fuel: Electricity-Coal Distortion: Transportation Regulation

Study: Friedlaender, A. F. 1971. "The Social Costs of Regulating the Railroad." The American Economic Review. LX(2):226-234.

Scope and

Method:

Friedlaender attempts to estimate two effects of I.C.C. railroad regulation, the divergence of price and cost and the extent that costs have been increased.

Findings: The loss due to excess costs is found to be fairly large somewhere between $\$ 2.4$ and $\$ 3.8$ billion in 1969 . On the other hand, the economy wide loss due to pricing inefficiencies is between $\$ 220$ million and $\$ 270$ million dollars. This smaller loss is made up of two components direct distortions in the railroad industry (between $\$ 98$ million and $\$ 229$ million) and smaller losses in other industries from high railroad prices.

Comments: The estimate of the pricing distortion is that prices are raised to about $147 \%$ of marginal costs. 
Study \# 16

Fuel: Natural Gas Distortion: Regulation

Study: Helms, R. B. 1974. Natural Gas Regulation, An Evaluation of FPC Price Controls. American Enterprise Institute, Washington, D.C.

Scope and

Method: Uses multiple regression to compare any changes in producer behavior after wellhead price control with their behavior in the period 1945-1960. The model is adequately described in an appendix. In addition to the quantitive modelling, Helms provides a study of history and results of FPC price controls on natural gas.

Findings: Helms concludes the regulations had little effect before 1967 due to declining market prices of gas from large discoveries. However, after 1967 the price controls encouraged the shortages of the early 70 s by not providing incentives for industry to respond to increases in demand for natural gas.

Comments: No attempt is made to estimate a free market price of natural gas. The evaluation of the shortage and history of regulation are very useful sources of information. 
Study

Fuel: 0 il

Distortion: Embargo

Study: Holcombe, R. G. 1974. The Economic Impact of an Interruption in United States Petroleum Imports: $1975-2000$, AD-AØ1ळ 914, National Technical Information Service, Springfield, Virginia.

Scope: A model was developed to project both aggregate and sector reductions in production which would result from an oil embargo.

Method: An 82 sector I-0 model was used with coefficients developed from 1967 data and data from the 1973-74 oil embargo. The model projects percentage reductions in SNP resulting from given levels of reduction in petroleum imports. The import reduction is assumed to last one year.

Findings: U. S. economic dependence on imported oil will increase through the year 2000 but at a decreasing rate.

Cost of a total embargo of ilideastern oil in 1980 - between $\$ 49$ and $\$ 117$ billion.

Comments: The estimates of impact of an oil embargo are for direct cost only. Both indirect costs and direct benefits, such as environmental damage avoided, are omitted from consideration. 
Study \# 18

Fue1: Coal Distortion: Environment

Study: Howard, H. A. 1977. "A Measurement of the External Diseconomies Associated with Bituminous Coal Surface Mining, Eastern Kentucky, 1962-1967." Natural Resources Journal. Vol. III, pp. 76-101, January 1977.

Scope: The study covers eastern Kentucky only.

Method: External costs are estimated on both per acre and per ton mined bases for the period from 1962-1967.

Findings: Costs per ton mined in 1967 were $\$ 0.027$. Tons mined increased over the study period while external costs per ton decreased. The sum of internal costs and enforcement expense per ton was found to have increased more than external costs decreased.

Study \# 19

Fuel: All Distortion: Environment and Health

Study: Hub, K. A., et al. 1973. A Study of Social Costs for Alternate Means of Electrical Power Generation for 1980 and 1990. Argonne National Laboratory, Argonne, Illinois.

Scope: Both internal and external costs are surveyed.

Method: Survey of studies and cost estimates to summarize available information on external costs.

Findings: Estimate of value for a large number of parameters.

Comments: Aesthetic damages and the health effects of emission from coal fired plants are omitted. Documentation of values is poor and there are significant gaps in the cost information such as the value of oil spill damages and nuclear waste disposal. 
Study \# 20

Fuel: $\quad$ Natural Gas

Distortion: Regulation

Study: Ives, E. E. and M. Holloway. 1977. Natural Gas Drilling:

An Economic Analys is of New Price Regulation with Emphasis on the Interstate and Texas Intrastate Markets, Executive Summary. Texas Governor's Energy Council, Austin, Texas.

Scope and

Method: Uses a mathematical model developed by the Governor's Energy Advisory Council which stimulates the interstate and Texas intrastate natural gas markets. They use the model with demand elasticitias from other studies to forecast market clearing prices for 1977 through 1980 and for 1985 under a variety of regulatory scenarios.

Findings: The predicted price is found to be very sensitive to the type of deregulation (i.e., rolled-in pricing results in a heavy increase in intrastate prices). Prices in 1985 could vary from $\$ 1.117 /$ Mcf to $\$ 2.1915 /$ Mcf. A scenario of allowing marginal cost pricing rather than rolled-in pricing, deregulation of oil prices, and the current boiler-fuel phase out scheme results in a price of about $\$ 1.83 / \mathrm{Mcf}$ (1975 dollars).

Comments: The model and the elasticities are neither shown nor discussed in the Executive Summary. 
Study \# 21

Fuel: Electricity Distortion: Regulation

Study: Kahn, A. E. 1970. The Economics of Regulation: Principles and Institutions. John Wiley and Sons, New York, NY.

Scope and

Method: The study provides a discussion of the role of economics in public utility regulation, details of the problems in estimating marginal costs and the effects of various pricing techniques.

Findings: Kahn proposes a variety of methods hoped to achieve price equal to long run marginal costs. He finds achievable pricing to be very different from setting price equal to short run marginal cost.

Comments: While the study does not provide any new estimates of pricing distortions, its footnotes provide a wealth of information and citations on past studies.

Study \# 22

Fuel: Natural Gas Distortion: Regulation

Study: Khazzoom, J. D. 1971. "The F. P. C. Staff's Econometric Model of Natural Gas Supply in the United States." Bell Journal of Economics and Management Science. 2(1):51-93.

Scope and

Method: Provides an econometric model of natural gas supply based primarily on technology. Uses data from 1961 to 1968 or 69 to construct the model.

Findings: Discusses the effects of various changes in the wellhead price on the supply and discovery of natural gas.

Comments: Supply variables are not as responsive to price as the MacAvoy Models. Comparison of the Khazzoom Model with the MacAvoy Model and the Erickson-Spann Model is provided in Pindyck's 1974 Bell Journal article. 
Study \# 23

Fuel: Natural Gas Distortion: Regulation

Study: Kitch, E. W. 1968. "Regulation of the Field Market for Natural Gas by the Federal Power Commission." Journal of Law and Economics. October 1968.

Scope and

Method: Kitch provides a historical narrative of F.P.C. regulation of natural gas, emphasizing court decisions particularly the Permain Basin decision and Phillips Petroleum vs Wisconsin.

Findings: The author evaluates the economics of the Supreme Court decisions and predicts the likelihood of natural gas shortages. He emphasizes the difficulties and inefficiencies of the multipriced system for gas.

Comments: No quantitative estimates of the unregulated price of gas are given.

Study \# 24

Fuel: Coal, Nuclear Distortion: Health Effects

Study: Lave, L. B. 1978. Quantification and Evaluation of Risks From Electricity Generation. Carnegie-Mellon University, Pittsburgh, Pennsylvania.

Scope: Risk estimates for a range of electricity generating technologies are compared.

Method: This is a survey of literature related to health effects of fuel extraction, transport, processing, and conversion processes.

Findings: Costs of health effects related to mining are $\$ .40$ to $\$ 5.30 / \mathrm{kWhr}$.e for coal and $\$ .024$ to $\$ .031 / 1000 \mathrm{kWhr}$.e for uranium.

Comments: The degree to which costs of health effects are internalized by producing firms is not treated so that estimates are of total costs rather than of health externalities. 
Study $\#$

Fuel: Natural Gas Distortion: Monopoly, Regulation

Study: Lee, M. 1974. State/Federal Regulation of Natural Gas. L/R-7, for the National Science Foundation, Washington, D.C.

Scope and

Method: The author compiles statements and conclusions from studies of the likelihood of the competitive pricing being reached in the absence of price controls and whether the original rationale of regulating a monopoly exists today. Lee also evaluates the possible government options to deal with the present shortage.

Findings: Lee concludes it is important to bring quantity supplied and quantity demanded into balance. He decides on the basis of available literature that natural gas would be workably competitive without regulation.

Comments: Good source on market structure of natural gas production. However, the summaries of "current" state and national legislation are quickly becoming dated. 
Study \# 26

Fuel: Electricity-Coal Distortion: Transportation Regulation

Study: Levin, R. C. 1978. "Allocation in Surface Freight Transportation Does Rate Regulation Matter?" The Bell Journal of Economics and Management Science. $9(1): 18-45$.

Scope and

Method: Attempts to estimate the ratio of price to variable costs as one step in estimating the welfare misallocation. The variable cost, defined as the optimal price, is obtained from I.C.C. data on variable costs and for one set of estimates is adjusted to reflect past criticisms of the I.C.C. allocation of fixed and variable costs.

Findings: Levins estimates the ratio of revenue to incremental costs to be 1.48 for boxcar and 1.17 for piggyback.

Comments: These estimates of the deadweight losses from regulated I.C.C. rates are lower than those obtained by Friedlaender. Levin attributes these differences in the demand elasticities used in the calculations and not differences in the extent of rate distortion. 
Study \# 27

Fuel: Natural Gas Distortion: Regulation

Study: MacAvoy, P.W. and R. S. Pindyck. 1973. "Alternative Regulatory Policies for Dealing with the Natural Gas Shortage," Bell Journal of Economics and Management Science. 4(2): 454-498.

Scope and

Model: $\quad$ The study evaluates possible policies for dealing with the natural gas shortages under 1) deregulation of wellhead prices, 2) increased regulation, and 3 ) continuation of status quo. They use an econometric model with both cross sectional and time series data from 1964 to 1971 to estimate supply and demand equations.

Findings: The projected price that would clear the market under a form of deregulation would be about $44.1 \$ /$ Mcf increasing by $3 \$ / y r$ to $62.0 \$ /$ Mcf by 1979. This market clearing price is found not to be particularly sensitive to the values of the exogeneous variables.

Comments: The values of many of the exogeneous variables for the past few years have not corresponded to the values assumed by the authors. For example, the real price of oil jumped dramatically in 1973-74 while the authors assumed a $5 \%$ real increase in these parameters. MacAvoy and Pindyck state the market clearing price is not particularly sensitive to the values of the exogeneous variables, their 1975 estimate is about $40 \% /$ Mcf larger than this estimate. 
Study \# 28

Fuel: Natural Gas Distortion: Regulation

Study: MacAvoy, P.W. and R. S. Pindyck. 1975. Price Controls and the Natural Gas Shortage. American Enterprise Institute, Washington, D.C.

Scope and

Mode 1: Describes a variety of improvements in the development of the M.I.T. natural gas model. Phase II of the model appeared in the Autumn 1973 Bell Journal, this version is phase III. The improvements are for heteroscedasticity and time series correlation. An increased data base is used for estimating the model.

Findings: Estimates a new contract price of $64.7 \$ /$ Mcf in 1975 increasing by about $7 \$ /$ Mcf per year to clear the market by 1980 when the price reaches about $100.3 \phi /$ Mcf. The authors believe this edition of the model to be superior due to the econometric improvements.

Comments: The improvements and reestimation of the model indicate some of the benefits from using an already constructed and tested model rather than resorting to the expensive procedure of developing an original model. 
Study \# 29

Fue1: 011 Distortion: Taxes and regulations

Study: MacAvoy, P. W., ed. 1977. Federal Energy Administration Regulation Report of the Presidential Task Force. American Enterprise Institute, Washington, D.C.

Scope and

Method: Provides an historical review of regulation of $0 i 1$ industry, especially of the post-OPEC period. Describes goals of current regulations, provides estimates of the costs to the industry of compliance, the costs to the taxpayer of the regulatory framework and analyzes the net benefits of current FEA regulatory program.

Findings: Petroleum industry reported compliance costs of $\$ 500$ million yearly, taxpayers paid $\$ 47$ million, FEA regulations were not effective in reducing prices because of discouragement of new refinery capacity and a variety of other cost increasing effects. The task force concludes the costs of the current program outweigh the benefits.

Comments: Doesn't explicitly calculate the price increases generated by regulation nor the reduction in price caused by entitlements. 
Study 30

Fuel: $\quad$ Electricity

Distortion: Regulation

Study: Marchand, D. J. and R. Sorensen. 1977. "Has Electricity Regulation Resulted in Higher Prices? Comment." Economic Inquiry, XV(4): $610-612$.

Scope and

Method:

The authors discuss the results of Moore (1975) who found that regulation may have incredsed the price of electricity. They discuss Moore's model and criticize the exclusion of a tax variable and propose alternative explanations for Moore's statistical finding.

Findings: The authors tend to place more reliance on the alternative explanations (historical, institutional, spurious correlation) than Moore's explanation that the utility regulation has increases utility prices.

Comments: The cited article is by C. G. Moore, "Has Electricity Regulation Resulted in Higher Prices? An Econometric Evaluation Utilizing a Calibrated Regulatory Input Variable." Economic Inquiry, XIII(3):207-220, 1975. 
Study \#31

Fuel: $\quad 0 i 1 \quad$ Distortion: Taxation

Study: McDonald, S. L. 1976. "Taxation System and Market Distortion." In Energy System and Government Policy. R. J. Kalter and W. A. Vogely, eds., Cornell University Press, I thaca, New York.

Scope and

Method: Discusses special taxation of oil and gas industries in relationship to the U.S. Corporate Income Tax. Discusses the changes in law as a result of the Tax Reduction Act of 1975 .

Findings: The special tax provisions applicable to oil and gas, particularly percentage depletion, likely result in large resource misallocation.

Comments: The analysis seems to be dated by the Tax Reduction Act of 1975 which essentially eliminates the depletion allowance for larger oil companies and drastically reduces it over the coming years for smaller firms.

Study \# 32

Fue1: 0 il Distortion: Taxation

Study: McDonald, S. L. 1976. "U.S. Depletion Policy: Likely Effects of Changes." Energy Policy. 4(1):56-63.

Scope and

Method: Discusses the changes and effects of the U.S. Tax Reduction Act of 1975, particularly the elimination of the percentage depletion allowance.

Findings: What consumers lose in higher prices from the Tax Act of 1975 they gain back from the gain they obtain as taxpayers. "The only sure losers, in the long run, are owners of land on which oil or gas has been found or may be found."

Comments: One of only a few studies analyzing the effects of elimination of the percentage allowance. 
Study \# 33

Fuel: $\quad 0 i 1 \quad$ Distortion: Regulation

Study: Mead, W. J. 1976. "Petroleum: An Unregulated Industry?" in Energy Supply and Government Policy. R. K. Kalter and W. A. Vogely, eds. Corne11 University Press, Ithaca, New York, pp. 130-192.

Scope and

Method: Mead provides descriptive history of regulation of the petroleum industry, particularly on prorationing, oil import quotas, and recent price controls and entitlement program.

Findings: Controls on the petroleum industry were intended to correct externalities resulting from law of capture, thereby eliminating physical waste. The industry used these regulations for their own good. The recent regulations thrust upon the industry have been punitive and undesired by the oil producers.

Comments: No evaluation of the costs of the programs or their effects on prices is attempted. 
Study \# 34

Fuel: Electricity Distortion: Regulation

Study: Moore, C. G. 1975. "Has Electricity Regulation Resulted in Higher Prices? An Econometric Evaluation Utilizing a Calibrated Regulatory Input Variable." Economic Inquiry. 13(3):207-220.

Scope and

Method: Using 43 investor-owned utilities in 26 states over four crosssectional studies, the author attempts to test econometrically the possibility that regulation has had no effect on utility prices.

Findings: "Regulation is not only unsuccessful in achieving its objective, it apparentiy has a perverse price effect and there is no indication that the situation is improving over time" (p. 213). The results seem to indicate regulation has increased the price of electricity possibly by attempting to cross subsidize customers, discriminating in favor of more numerous smaller users of electricity.

Comments: See the study by Jay Marchand and Robert Sorensen for a rebuttal. 
Study $\# 35$

Fuel: Electricity-Coal Distortion: Transportation Regulation

Study: Moore, T. G. 1975. "Deregulating Surface Freight Transportation." in Promoting Competition in Regulated Markets. Almarin Phillips, ed. The Brooklings Institution, Washington, D.C.

Scope and Method:

The author attempts to estimate the costs of regulation for all modes of transportation regulated by the I.C.C. For railroads, Moore attempts to estimate the decline in rates that would occur. Assuming total deregulation in transportation, the same amount of railroad traffic after deregulation, Moore uses estimates that truck prices would fall by $20 \%$ and a demand elasticity of -1 for railroads to estimate the price reduction necessary for railroads to maintain volume.

Findings: Moore estimates prices would fall by $20 \%$ to calculate the losses from transportation regulation. In addition, he provides estimates of the ratio of revenue to out of market costs. Coal's ratio of 1.01 is among the lowest although these costs may be altered because unit trains are not considered.

Comments: The study gives some support that the price of coal transportation by railroads might fall in the absence of regulation. However, $20 \%$ may be too high if the ratio of revenue to out-of-pocket costs for coal is close to the lowest of all shipped commodities. Compare this study with those of Friedlaender, 1969 and 1971. 
Study $\# \quad 36$

Fuel: Electricity-Coal Distortion: Transportation Regulation

Study: Moore, T. G. 1972. Freight Transportation Regulation. American Enterprise Institute, Washington, D.C.

Scope and

Method: Moore provides a historical description of freight transportation regulation and how it presently operates. A comparison of various studies predicting the potential price reduction from deregulation is presented. By examining the number of requests for price increases or decreases made to the I.C.C. by various modes of transportation, a qualitative estimate of the direction of movement from dereguiating price is made.

Findings: The rates for rail carriers are expected to fall but no estimate is provided for the magnitude. However, estimates given for the fall in truck rates range between $7 \%$ and over $20 \%$. 
Study \# 37

Fuel: Coal Distortion: Land Use, Health and Environmental Damage

Study: Morgan, M. G., B. R. Barkovich and A. K. Meier. 1973. "The Social Costs of Producing Electric Power from Coal: A First-Order Calculation." In Proceedings of the IEEE. 61(10).

Scope: This study covers externalities resulting from the extraction and conversion of coal for power production. The cost estimates are based on mid-to-late 1960 s prices and technology.

Method: The literature was surveyed for estimates of some of the components of total social cost of power production from coal. There is evidence that each of the cost estimates is conservative and that the summation of these understated cost components may lead to significant understatement of total social cost. Where cost estimates were made for all production, costs are distributed based on the percentage of total coal production used for electricity.

Findings: The sum of minimum reasonable estimates of social costs surveyed was found to exceed the price of bulk power at the plant bus bar $(>11.5 \pm 2 \mathrm{mil1} \mathrm{s} / \mathrm{kWh})$ as of the late 1960s.

Comments: No aesthetic costs are included. 
Study \#38

Fuel: Electricity-Coal Distortion: Monopoly

Study: Moyer, R. 1974. "The Coal Industry." In Competition in the U.S. Energy Industry. T. D. Duchesneau, ed., Ballinger Publishing Co., Cambridge, MA.

Scope and Method:

This study examines capital costs of entry in coal mining, especially costs for entry into coal gasification plants. The author also looks at the effects of the shift to Western low sulfur coal on U.S. market structure. To estimate the costs associated with market entry, Moyer examines actual operating and capital costs for a new mine as well as secondary data.

Findings: Two-thirds of the coal firms are not represented in the expanding low-sulfur coal region. The number of firms operating in the Montana, Wyoming, North Dakota region is only 16, with the government being the largest single owner of reserves.

Comments: Although the ownership of the Western coal is relatively concentrated, the addition of this source of coal and the difference in ownership patterns between western and Eastern coal should serve to reduce concentration. 
Study \# 39

Fuel: Natural Gas Distortion: Regulation

Study: Neri, J. A. 1977. "An Evaluation of Two Alternative Supply Models on Natural Gas." Bell Journal of Economics and Management Science. $8(1): 289-302$.

Scope and

Method: Evaluates two models of the natural gas industry, the MacAvoyPindyck MIT model with the American Gas Association TERA modal by simulation over 1967-1972 and a comparison of predictions over the period 1975 to 1980 . Evaluation is made on equations predicting the number of wells, new discoveries, additions to reserves and production on the bas is of lower root mean square error.

Findings: The author makes no attempt at using the models to predict an unregulated price. Both models seem to perform equally well on the 1967-1972 simulation period but are found to diverge in the forecast period of 1975 to 1980 .

Comments: The TERA model relies very little on price. It seems to underpredict the effect of regulation. Neri believes the MacAvoyPindyck model to overestimate responsiveness of production to price. The divergence in the forecast period causes some concern since very different price effects are associated with deregulation. 
Study \# 39A

Fuel: All Distortion: Environmental Damage

Study: $\quad$ Newkirk, H. W. 1976. Environmental Effects of Energy Production and Utilization in the U.S., Vols, I and II. University of California, Livermore, California.

Scope: Description of sources, trends and costs of control for environmental and health damages.

Method: This is a summarization and synthesis of previous research.

Findings:

Comments: Comprehensive review of published research. 
Study \# 40

Fuel: Coal Distortion: Environmental

Study: North, D. W. and M. W. Merkhofer. 1975. "Analysis of Alternative Emissions Control Strategies." Air Quality and Stationary Source Emission Control, National Academy of Sciences, Washington, D.C.

Scope: The marginal cost of increases in sulfur oxide emissions is computed for the N. E.

Method: A detailed model is developed to estimate both health and materials damaged from sulfur emissions from coal fired thermal power plants. The difference in effects of rural and urban plant sites is considered and there is a sensitivity analysis for value assumptions used in deriving cost estimates.

Findings: Total annual health costs ranged from 12.9 to 38.3 million dollars depending on siting of the plant in a remote or urban area. The comparable range of material damage costs was from $\$ 7.2$ to $\$ 14.8$ million. The annual cost per pound of sulfur emitted was $\$ .21$ in a remote location and \$.55 in an urban area. There is evidence that these estimates are low.

Comments: This is a rigorous and relatively comprehensive attempt to quantify costs of coal combustion emissions to society. The methodology developed is suitable for use in economic valuation of a variety of externalities. 
Study 41

Fuel: $\quad$ Natural Gas

Distortion: Regulation

Study: Pindyck, R. S. 1974. "The Regulatory Implications of Three Alternative Econometric Supply Models of Natural Gas." Bell Journal of Economics and Management Science. 5(2):633-6 $\overline{45}$.

Scope and Method:

Pindyck evaluates three major natural gas econometric models (MacAvoy-Pindyck, Khazoom, and Erickson-Spann) by estimating over a consistent time period. The author discusses the differences in the models and the effects of the structural differences on the values of the remaining coefficients.

Findings: No new estimates of the deregulated price of natural gas. The Khazzoom model was found to be relatively price insensitive. The coefficients of the models change when they are reestimated implying either possible structural change or misspecification. While these represent "state-of-the-art" modeling the conclusions and policy decisions are sensitive to the model used.

Comments: The MacAvoy-Pindyck model appears to perform "better" than the other two models. 
Study \# 42

Fuel: Coal

Distortion: Environmental Damage

Study: Randal1, A., et al. 1978. Estimating Environmental Damages From Surface Mining of Coal in Appalachia: A Case Study. EPA-600/ 2-78-003, Environmental Protection Technology, Washington D.C.

Scope: A method of valuing the environmental damage from surface mining is developed and tested on a 6 county mining region of Kentucky.

Method: An environmental damage production function is developed and used in estimation of the net present value of changes in resource quality brought about by mining. A bidding-game survey was undertaken to provide values for the changes in resource quality.

Findings: Net present value (N.P.V.) of aesthetic, water quality, flooding, land and building, and fish, wildlife and recreation damages is $\$ 9.14 /$ metric ton when all consumers of coal products are considered willing to pay for aesthetic damages. If only regional residents are counted, the N.P.V. is $\$ 0.40 /$ metric ton.

Comments: This study could be used as a basis for estimating environmental damage costs of surface mining in Appalachia. 
Study 43

Fuel: Coal, Nuclear Distortion: Health Effects

Study: Sagan, L. A. 1974. "Health Costs Associated with the Mining, Transport and Combustion of Coal in the Steam-electric Industry." Nature, 250:107-111, July 12, 1974 .

Scope: Costs of morbidity and mortality are estimated for mining, transportation accidents and air pollution.

Method: Costs are derived through the aggregation of secondary data.

Findings: $50 \%$ of the health costs associated with coal result from the mining process. The annual health costs for a $1000 \mathrm{MW}$ coal plant are $\$ 1,252,000$ and for a comparable nuclear plant $\$ 217,000$.

Comments: Estimates are rough and those for air pollution effects are especially weak. 
Study $\# \underline{44}$

Fuel: $\quad$ Electricity Distortion: Regulation - Peak Load Pricing

Study: Sharefkin, M. 1974. The Economic and Environmental Benefits from Improving Electrical Rate Structures. EPA-600, National Technical Information Service, Springfield, Virginia.

Scope and

Method:

Estimates are derived for the cost savings from changes in the pricing of electric power. Using elasticity values from previous econometric studies as parameter values, allows estimation of the benefits. Particulariy examined are the effects of peak load pricing, both time of day and seasonal.

Findings: The recommended reduction for residential customers' off-peak prices was from $0.02476 \$ / \mathrm{kWh}$ to $0.014 \$ / \mathrm{kWh}$, similarly, the author recommended an increase in peak time rates of $0.063 \$ / \mathrm{kWh}$. These numbers are derived from one utility and do not represent a generalized estimate. The author also concludes "average pricing substantially underprices peak period power" (p. 121).

Comments: The implication of the study for measuring distorticns is that off-peak prices are too low and peak prices too high. Thus, the appropriate correction is not merely a correction of the distortion but separation of power into two products with two prices peak and off-peak. 
Study \# 45

Fuel: $\quad$ Electricity Distortion: Regulation

Study: Stigler, G. J., and C. Friedland. 1962. "What can Regulators Regulate? The Case of Electricity." Journal of Law and Economics. Volumn IV.

Scope and

Method: Stigler and Friedland attempt to evaluate if regulation has had any effect on the price of electricity. By multiple regression on data from 1912 to 1937, they test the hypothes is with average revenue per $\mathrm{kWh}$ as the dependent variable and several independent variables including a dummy variable for the presence of regulation.

Findings: The authors could find no evidence that regulation had any effect on the average level or rates. The regulatory body was incapable of forcing the utility to operate at a specified combination of output, price and cost.

Comments: This article drew responses from a variety of critics because of its conclusion that utility regulation was ineffective in lowering utility prices. It spawned a host of research into the real effects of regulation which often have turned out very different than announced goals. 
Study $\#$

Fuel: $0 i 1 \quad$ Distortion: Monopoly

Study: $\quad$ Sunder, S. 1977. 0il Industry Profits. American Enterprise Institute, Washington, D.C.

Scope and

Method: Discusses several methods of measuring profits, capital marketbased measures and numerous variations of accounting measures. The author estimates a variety of profit rates for oil firms both integrated and specializing at one level and compares them with non-0il manufacturing firms.

Findings: Judged by accounting rates, the oil industry has been no more profitable than other industrial firms. The increase in price of oil has lead to a transient increase in profits for the past two years. Using market data, the oil industry has performed better than average. He attributes this performance to an improvement in prospects over these years.

Comments: Supplies a wealth of data on oil company profitability measured in a number of ways. 
Study \# 47

Fue 1: $0 i 1 \quad$ Distortion: Embargo Costs

Study: Tani, S. N. and D.W. Boyd. 1976. Measuring the Economic Cost of an 0 il Embargo. Stanford Research Institute, Menlo Park, California.

Scope: A method is developed for estimating the economic losses associated with curtailment of oil supplies.

Method: Measures based on G.N.P., and on consumer and producer surpluses are composed. The method developed aggregate estimates of consumer and producer surplus for all sectors of the economy.

Comments: Strong assumptions would be required to simplify the data requirements for use of this method. 
Study \# 48

Fuel: $\quad 011$, Gas, Coa1, Nuclear, Hydro Distortion: External Costs

Study: U.S. Atomic Energy Commission. 1974. Comparative Risk-Cost-Benefit Study of Alternative Sources of Electrical Energy. WASH - 1224, U. S. Government Printing Office, Washington, D.C.

Scope: This study was designed to provide a comprehensive comparison of the conventional and external costs of the various sources of electrical energy.

Method: Cost estimates for damage functions were taken from the literature and added to estimate total social cost. Methods and assumptions underlying the estimates are carefully documented. The estimates derived are minimums since many categories of social cost are omitted from consideration or lack value estimates.

Findings: External costs were found to add no more than $3 \%$ to conventional costs.

Comments: The health effects of emissions from coal burning are not evaluated. 

PNL -3087

UC-95d

\section{DISTRIBUTION}

No. of

Copies

OFFSITE

No. of

Copies

42 Pacific Northwest Laboratory

R. C. Adams

J. W. Currie

D. E. Deonigi

T. J. Foley

L. A. Nieves (10)

R. L. Nesse

Economics Library (20)

Technical Information Files (5)

Publishing Coordination WI (2)

J. Binkley

U.S. Department of Energy

Washington, DC 20545

M. Savitz

U.S. Department of Energy Washington, DC 20545

J. Cable

U.S. Department of Energy

Washington, DC 20545

P. Back

U.S. Department of Energy

Washington, DC 20545

J. Willman

U.S. Department of Energy

Washington, DC 20545

C. L. McDonald

Mathematical Sciences Northwest, Inc.

P.0. Box 1887

Bellevue, WA 98009

\section{ONSITE}

DOE Richland Operations

H. E. Ransom 
. 